\title{
Engineering metal (hydr)oxide sorbents for removal of arsenate and similar weak-acid oxyanion contaminants: A critical review with emphasis on factors governing sorption processes
}

\author{
Kiril D. Hristovski*, Jasmina Markovski \\ Sonoran Arroyo Mall, Mesa, AZ 85212, United States \\ * Corresponding author \\ Tel.: +1 4807271291 \\ E-mail address: Kiril.Hristovski@asu.edu
}

The Polytechnic School, Ira A. Fulton Schools of Engineering, Arizona State University, 7171 E. 


\begin{abstract}
To create an integrative foundation for engineering of the next generation inexpensive sorbent systems, this critical review addresses the existing knowledge gap in factor/performance relationships between weak-acid oxyanion contaminants and metal (hydr)oxide sorbents. Indepth understanding of fundamental thermodynamics and kinetics mechanisms, material fabrication, and analytical and characterization techniques, is necessary to engineer sorbent that exhibit high capacity, selectivity, stability, durability and mass transport of contaminants under a wide range of operating and water matrix conditions requirements. From the perspective of thermodynamics and kinetics, this critical review examines the factors affecting sorbent performances and analyzes the existing research to elucidate future directions aimed at developing novel sorbents for removal of weak-acid oxyanion contaminants from water. Only sorbents that allow construction of simple and inexpensive water treatment systems adapted to overcome fiscal and technological barriers burdening small communities could pave the road for providing inexpensive potable water to millions of people. Novel sorbents, which exhibit (1) poor performances in realistic operating and water matrix conditions and/or (2) do not comply with the purely driven economics factors of production scalability or cost expectations, are predestined to never be commercialized.
\end{abstract}

Keywords: arsenic; oxyanions; sorbent; sorbate; water treatment; metal (hydr)oxide nanomaterial 


\section{Introduction}

Anthropogenic pollution and extensive overuse of water for domestic, agricultural, and industrial applications threaten to deplete the existing fresh water resources in the near future (Bouwer, 2000; Helweg, 2000; Hoekstra and Mekonnen, 2011). Providing access to potable water, which already represents a major problem for many communities in the developing world, is projected to transcend the national geo-economic boundaries and become an imperative global issue (Bogardi et al., 2012; Bundschuh et al., 2010; Cohen et al., 2004; Mutikanga et al., 2009; Ravenscroft et al., 2009; van der Bruggen and Borghgraef, 2010; Wescoat et al., 2007). Existing water treatment technologies, which are typically applicable to large communities, become economically infeasible when scaled-down to serve the needs of smaller communities (Berg, 2015; Litter et al., 2012; Wilcox et al., 2010). Small communities typically rely on groundwater as their potable water source and often lack financial, infrastructural, or technical resources to operate complex water treatment systems capable of simultaneously removing multiple contaminants (Brennan and McBean, 2011; Dawoud and Raouf, 2009; Foster and Chilton, 2003; Wilcox et al., 2010). These challenges are especially cumbersome in environments where geological formations promote dissolution of weak-acid oxyanion species, like arsenic, vanadium, or antimony, which cause chronic toxicity and require innovative treatment approaches (Filella et al., 2002; Gao et al., 2011; Goh and Lim, 2004; Gorny et al., 2015; Smedley and Kinniburgh, 2002; Szrameka et al., 2004). Development of simple and inexpensive groundwater treatment systems, which are (1) tailored to simultaneously remove multiple oxyanionic contaminants with specific chemistries and (2) adapted to overcome fiscal and technological barriers burdening small communities, could pave the road for providing inexpensive potable water to millions of people.

Sorbents represent an ideal platform for engineering simple and inexpensive systems capable of simultaneously removing multiple harmful weak-acid oxyanions from complex water matrices. In the last two decades, there has been a rapid expansion in development of novel sorbents for treatment of weak-acid oxyanions (Bang et al., 2011; Ippolito et al., 2011; Mohan and Pittman, 2007; Möller, 2011; Westerhoff et al., 2006). However, the majority of this work has been based on the trial and error approach, rather than on a fundamental understanding of the physico-chemical principles that govern the performances of a sorbent in a given groundwater 
matrix (Bleiman and Mishael, 2010; Camacho et al., 2011; Diamadopoulos et al., 1993; Duc et al., 2006; Gibbons and Gagnon, 2011; Kamei-Ishikawa et al., 2008; Maeda et al, 1990; MonteilRivera et al., 2000; Ramana and Sengupta, 1992; Park and Kim, 2011; Pillewan et al., 2011; Pirilä et al., 2011; Prathap and Namasivayam, 2010; Saikia et al., 2011; Sari et al. 2012; Suzuki et al, 1997; Li et al. 2011; Ma and Tu, 2011; Mariussen et al., 2012; Mohan and Pittman, 2007; Mostafa et al., 2011; Mou et al., 2011; Rovira et al., 2008; Tanboonchuy et al., 2011; Watkins et al., 2006; Wei et al., 2012; Yang et al. 2011; Zhang et al., 2009a, 2009b; Zheng et al., 2011). A comprehensive understanding of the sorbent/sorbate interactions in complex water matrices represents a cornerstone in developing the next generation of sorbents, which should exhibit high selectivity and capacity for removing toxic weak-acid oxyanions from water. Only by bridging this fundamental knowledge with existing macroscopic engineering concepts, successful development of the next generation sorbent based systems could be accomplished.

Transition metal (hydr)oxides, such as ferric (hydr)oxides or titanium dioxide, have been widely used for removal of oxyanion contaminants from water (e.g. arsenic, antimony, selenium, vanadium, etc.) (Bortun et al., 2010a; Hodi et al., 1995; Hristovski et al., 2007; Jordan et al, 2013a; Naeem et al., 2007; Nguyen et al., 2011; Peraniemi et al., 1994; Pierce and Moore, 1980, 1982; Westerhoff et al., 2006; Xu et al., 2012). Although many of these studies provide a partial description of how sorption of weak-acid oxyanions on metal (hydr)oxide surfaces is influenced by the fundamental factors, they do not address the theoretical and practical aspects of the problem in context of developing a solution oriented platform that could serve as a tool for addressing real world problems. In depth understanding of these factors, organized in a conceptual framework that contextualizes their practical applicability, provides a foundation for engineering the next generation of high performance sorbents for removal of toxic weak-acid oxyanion contaminants from complex water matrices.

In order to create an integrative foundation for engineering of the next generation inexpensive sorbent systems, this critical review addresses the existing knowledge gap in factor/performance relationships between weak-acid oxyanion contaminants and metal (hydr)oxide sorbents. To accomplish the goal of this study: (1) sorbent performance requirements are summarized; (2) determinants engaged in the process of sorbent-engineering are characterized; (3) main factors controlling these determinants are systematically examined. 


\section{Conceptual framework for engineering the next generation of sorbents}

Conceptual frameworks often represent a beneficial tool that helps contextualize the unique challenges emerging from development and implementation of novel technologies. A conceptual framework that describes the determinants engaged in the process of engineering novel sorbents is illustrated in Figure 1.

\section{$<$ Figure 1 >}

Engineering the next generation sorbents is primarily directed by the relatively invariable performance requirements. In brief, the sorbents must (1) exhibit high selectivity and capacity for specific contaminants; (2) allow for fast mass transport of contaminants; (3) minimize operational and maintenance requirements when operated in full-scale applications; and (4) be inexpensive and simple to fabricate when compared to other water treatment technologies. Successful fulfillment of these requirements necessitates a solid understanding of thermodynamics, kinetics, material fabrication, and analytical and characterization techniques. Thermodynamics actuates the sorption capacity, selectivity, and stability of a sorbent. Change in thermodynamic conditions, such as change in sorbate concentration or chemistry, could significantly affect these key sorbent properties. Other sorbent properties, such as particle size and porosity, significantly influence kinetic parameters, like intraparticle and external (film) mass transport processes, that affect the design of a sorbent system. A comprehensive understanding of material fabrication and characterization is imperative for tailoring sorbent characteristics to fit desired performances for specific water matrices. Considering the interdependence of these factors, a holistic approach in developing the next generation sorbents becomes paramount. This holistic approach, however, mandates an in-depth understanding of the relationships among these factors, their prevalence, and the challenges stemming from them.

\section{Factors governing the sorption thermodynamics}

\subsection{The chemistry of weak-acid oxyanion sorption onto metal (hydr)oxides}


Empty $d$ orbitals in a transitional metal act as Lewis acids for the oxyanions' electron rich oxygen atoms (Kutzelnigg, 1984; Sherman, 1985; Stair, 1982, 1991). Consequently, weak-acid oxyanion contaminants sorb onto metal (hydr)oxide surfaces by creating oxygen bridges via ligand exchange with $\mathrm{OH}^{-}$or $\mathrm{OH}_{2}$ groups located on the sorbents' surface and form stable monodentate or bidentate inner-sphere complexes, although recent evidence suggests that tridentate complexes could also be formed under specific conditions (Figure 2) (Breynaert et al., 2008; Goldberg and Johnston, 2001; Grossl et al., 1997; Ippolito et al., 2009; Jin et al., 2007; Lange et al., 1991; Manning et al., 2002; Mitsunobu et al., 2009, 2010; Otte et al., 2013; Peak, 2006; Rakshit et al., 2011; Wang et al., 2011; Waychunas et al., 1993, 1995a).

$<$ Figure 2>

The thermodynamic stability of formed inner-sphere complexes is strongly dependent on the number of formed oxygen bridges, the orientation and proximity of the populated Lewis acid sites, and the relative surface loading (Fendorf et al., 1997). For example, the modeled Gibbs free energy change of reaction between $\mathrm{AsO}_{4}$ tetrahedra and $\mathrm{FeO}_{6}$ octahedra amounts $<-58 \mathrm{~kJ} / \mathrm{mol}$ for monodentate and almost doubles to $<-100 \mathrm{~kJ} / \mathrm{mol}$ for bidentate surface complexes with a net charge of zero (Farrell and Chaudhary, 2013). Bidentate corner-sharing complexes (Figure 3 (a)) between ferric (hydr)oxides surfaces and weak-acid oxyanions, like vanadate and arsenate, are considered more favorable and thermodynamically more stable than a bidentate edge-sharing complexes (Figure 3 (b)) (Majzlan, 2010; Peacock and Sherman, 2004; Sherman and Randall, 2003).

$<$ Figure 3>

Such conclusion is based on the shorter distances between two available Lewis acid sorption sites in an edge-sharing complex that cause the angle between the two oxygen bridges to decrease, consequently stressing the bonds and creating a less thermodynamically stable complex. This energetic difference is quantified and for arsenate and ferric (hydr)oxide amounts to about $55 \mathrm{~kJ} / \mathrm{mol}$ (Sherman and Randall, 2003). In monodentate complexes, the oxygen bridge is not subject these bond-angle induced stresses; however, studies have shown that this complex 
is less thermodynamically stable than bidentate complexes due to absence of a reinforcing effect provided by a second oxygen bridge (Han et al., 2010; Manceau and Charlet, 1994; Manceau, 1995). However, according to the meta-stable theory, stable mododentate complexes form when the sorbate/sorbent ratio is high or as an intermediary phase in forming of bidentate complexes (Farrell and Chaudhary, 2013; Fendorf et al., 1997; Jain et al., 1999; Pan and Liss, 1998a, 1998b; Waychunas et al., 1995b). In the latter case, these transient monodentate complexes cannot be even isolated due to its instability which makes its nature controversial (Manceau, 1995; Sherman and Randall, 2003; Waychunas et al., 1993).

Interestingly, but no systematic study based on experimentally obtained sorption data has been made to clarify presented modeling calculations and point to stability of complexes created between commercial metal (hydr)oxide sorbents and weak-acid oxyanion contaminants in realistic conditions. Although some studies covered sorption thermodynamic, reported data are highly inconsistent (Nordstrom and Archer, 2003). This is not surprising considering that partitioning or other inadequate constants have frequently been used to describe the changes of Gibss free energy of sorption (Liu, 2009). These approaches have resulted in incorrect calculation of thermodynamic parameters and unrealistic values that describe physico-sorption rather than chem-sorption processes (Chowdhury et al., 2011; Gupta and Ghosh, 2009; Maji et al., 2011; Park et al., 2009; Simsek et al., 2013; Tuna et al., 2013; Vitela-Rodriguez et al., 2013).

\subsection{Influence of sorbent properties on sorption thermodynamics}

High surface area and density of Lewis acid sites, however, are not the only factors that govern the formation of more thermodynamically stable complexes. Crystalline structure and morphology of metal (hydr)oxide materials determine both the orientation and number of Lewis acid sites available for formation of monodentate or bidentate inner-sphere complexes. For example, anatase is a better performing arsenic sorbent than rutile although both materials are comprised of slightly distorted titanium centered octahedral units (Diebold, 2003). This lower sorption capacity of rutile could be partially attributed to the fact that the angles and bond lengths in rutile octahedral configuration are different than the ones in anatase. The angles between two Ti-O bonds in rutile are $<99^{\circ}$, which possibly makes them unsuitable for creating stable bidentate complexes. In contrast, the slightly distorted octahedral cell units in anatase are 
characterized with one of the Ti-O angles being $102.3^{\circ}$, which is similar to As-O angle of $109.5^{\circ}$ in arsenate (Diebold, 2003; Sherman and Randall, 2003). Considering the comparable bond lengths in anatase and arsenate $\left(l_{\mathrm{Ti}-\mathrm{O}} \sim 1.95 \AA\right.$ and $\left.l_{\mathrm{As}-\mathrm{O}} \sim 1.72 \AA\right)$, it is reasonable to hypothesize that these stereochemical specifics significantly contribute to more thermodynamically favorable inner-sphere bidentate complexes. Similarly, additional evidence emerging from studies with other metal (hydr)oxides further supports the hypothesis that metal (hydr)oxide sorbents with specific crystalline structure and morphology promote formation of inners-sphere complexes with weak-acid oxyanion species (Canecka et al., 2011; Hong et al., 2010; Jegadeesan et al., 2010; Müller et at., 2010; Waychunas et al., 1995b). For example, hematite is comprised of octahedral cell unit characterized by Fe-O bond lengths $\sim 1.95 \AA$ and one of O-Fe-O bond angles being $\sim 102.5^{\circ}$ (Blake and Hessevick, 1966). These basic cell unit characteristics are very similar to the ones found in anatase, but significantly different than the one of rutile.

Arrangement of sorbent structure also exerts influence on its capacity. For example, arsenate complexes on amorphous $\mathrm{FeOOH}$ are more structurally disordered than on crystalline ferric (hydr)oxide. Even bidentate site attachment should be thermodynamically and kinetically favored over monodentate attachment, more randomly organized structure of amorphous $\mathrm{FeOOH}$ promote formation of monodentate complexes because the contribution of "angle factors" are reduced (Waychunas et al., 1993). Due to contribution of monodentate complexes under realistic conditions, higher capacity of arsenic is frequently expected to be achieved by amorphous $\mathrm{FeOOH}$.

In addition to affecting the stereochemical specifics of a sorption process, crystallinity and morphology also influence the surface charge of metal (hydr)oxides at given pH. For example, synthetically derived hematite typically exhibits an iso-electric point ( $\mathrm{pH}_{\mathrm{ISO}}$ ) between 8.1 and 8.8, while other $\mathrm{Fe}_{2} \mathrm{O}_{3}$ crystalline structures might exhibit $\mathrm{pH}_{\text {ISO }}$ of about 7.2 (Kosmulski et al., 2003). Crystallinity and morphology determine the density of Lewis acid sites on a metal (hydr)oxide surface, which consequently contributes to the overall surface charge (SalazarCamacho and Villalobos, 2010; Villalobos et al., 2009).

In contrast, electronegativity of the metal cation and its charge and radius determine the strength of a Lewis acid site. Transitional metal (hydr)oxides comprised of metals with higher electronegativity and higher $q^{2} / r$ ratios, where $q$ and $r$ are the charge and radius of the metal cation, exhibit higher iso-electric points (Gaskov and Rumyantseva, 2008). For example, 
considering that nickel is more electronegative than titanium or iron, it is understandable why nickel oxide exhibits higher iso-electric point than titanium dioxides or ferric (hydr)oxides (Greenwood and Earnshaw, 1998; Hristovski et al., 2007; Kosmulski, 2002; Kosmulski et al., 2003). Sorbents with high iso-electric points reduce sorption energy requirements by decreasing the electrostatic repulsion forces that exist between the sorbent surface and negatively charged oxyanions in $\mathrm{pH}$ environments greater than the metal (hydr)oxide's iso-electric points. Some metal (hydr)oxides with high iso-electric points, like hematite, goethite or nickel oxide, exhibit positively charged surfaces in $\mathrm{pH}$ environments representative of natural waters, which promote sorption by inducing electrostatic attraction, instead of repulsion, between these surfaces and the negatively charged oxyanions (Hristovski et al., 2007; LeMire et al., 2010; Mustafa et al., 2010). The electrostatic attraction reduces the overall sorption energy requirements, which becomes evident by a decrease in the Freundlich sorption intensity parameter $(1 / n)$ when the $\mathrm{pH}$ is decreased. The Freundlich sorption intensity parameter is directly related to the mean sorption energy of a Lewis acid site and its enthalpy change as described by Equation 3.1 (Crittenden et al., 2005; Elton et al., 2013; Halsey and Taylor, 1947):

$$
n=\frac{\Delta H_{M}^{o}}{R T}-r \frac{\Delta H_{s o r b}^{o}}{R}
$$

where $\Delta H^{o}{ }_{M}$ and $\Delta H^{o}$ sorb are the mean sorption site energy and change in site enthalpy, respectively; $R$ is the universal gas constant; $T$ is the thermodynamic temperature; and $r$ is a proportionality constant. As evident from Equation 3.1, temperature affects the sorption energy and could lead to formation of less thermodynamically stable complexes, different adsorption capacity and faster adsorption kinetic (Ambe, 1987; Banerjee et al., 2008; Jordan et al., 2013b).

Materials with high iso-electric points generally favor sorption of weak-oxyanions and may exhibit higher sorption capacities because of the attractive Coulumbic interactions between Lewis acid sites (e.g. protonated sorbent surface groups) and negative sorbate ions (Banerjee et al., 2008; Pierce and Moore 1982; SenGupta and Greenleaf, 2002). In contrast, although many sorbents, which have low iso-electric points (e.g. zeolites, silica), may exhibit large surface areas and porosities, they hinder any sorption because of unfavorable energy of complex formation caused by repulsive electrostatic interactions between the negatively charged surfaces and sorbate anions at $\mathrm{pH}$ values of natural waters.

The presence of stronger Lewis acid sites on the surface of a metal (hydr)oxide sorbent 
raises its isoelectric point, consequently reducing the sorption energy requirements (Kataoka and Dumesic, 1988). However, metal (hydr)oxides with high isoelectric points are more prone to dissolution, especially in mildly acidic environment (Bondietti et al., 1993). For example, nickel oxide dissolves in water with $\mathrm{pH}<7$ (Hristovski et al., 2007), while the dissolution of ferric (hydr)oxides is promoted by a decrease in pH (Cornell and Schwerman, 2003). In contrast, titanium and zirconium oxide, which exhibit weaker Lewis acid sites than nickel oxide, are stable even in strong acids.

Introduction of electronegative transitional metal cations with unpopulated $d$ orbitals into the crystalline lattices of more non-soluble metal (hydr)oxides should increase the isoelectric point of sorbent and contribute to lowering of the sorption energy requirements. A limited number of studies have been published that actualize this hypothesis; however, systematic exploration has not been conducted to verify and describe these principles in the context of engineering sorbents for removing weak-acid oxyanions (Davis and Mishra, 1997; Dou et al, 2011; Nilchi et al., 2011; Ren et al., 2011; Szlachta and Chubar, 2013; Yin et al., 2011). Published evidence also supports a hypothesis that doping with more transitional metal cations reduces dissolution of some metal (hydr)oxides (Chen et al., 2007; Deng et al. 2010; Li et al., 2012; Sun et al., 2009; Xu et al., 2011), however, systematic studies have not been conducted to examine the stability of doped metal (hydr)oxides or composites when exposed to realistic groundwater matrices.

The infrequently published studies clearly imply that modification of the basic cell unit characteristics by introducing specific metal cations into the structure of the metal (hydr)oxide (doping) could be used as a tool to produce sorbents with stereochemical specifics capable of promoting the sorption process and improving selectivity and sorption capacity (Deng et al., 2010; Dou et al., 2011; Hana, et al., 2016; Liu et al., 2010; Thi et al., 2015; Zhang et al., 2010). On the example of chromate and selenite adsorption on Al-substituted ferrihydrite, higher adsorption capacity has been explained as a result of significant increase of less thermodynamically stable outer-sphere complexes with increasing Al substitution (Johnston and Chrysochoou et al., 2016). Systematic studies, however, that examine the factors affecting the doping induced stereochemical specifics of sorption have not been conducted.

An alternative approach for minimizing the energy of sorption is by engineering hybrid sorbents, which represent a class of sorbents comprised of two or more distinctive materials 
designed to improve physical and chemical sorbent performances and/or simultaneously remove multiple contaminants that exhibit different chemistries. The physico-chemical properties of the base sorbent media may influence the overall performance of the hybrid sorbent to sorb weakacid oxyanions. Surface area, surface charge, presence of oxygen containing or oligomeric groups, and pore-size distribution of the base media influence the formation and distribution of metal (hydr)oxide nanoparticles inside the pores of the base media, which consequently affects the hybrid sorbent's performance (Chang et al., 2010; DeMarco et al., 2003; Hristovski et al., 2009; Yan et al., 2011). For example, lignite based granular activated carbon (GAC) provides hybrid sorbents with higher content of ferric(hydr)oxide nanoparticles than bituminous based GAC (Cooper et al., 2010; Deliyanni and Bandsoszm, 2011). The underlying hypothesis suggests that a greater macroporosity and highly oxidized surfaces provide a better environment for in-situ synthesis of ferric (hydr)oxide nanoparticles because of better accumulation and concentration of ferric ions inside the pores before in-situ nanoparticle formation is initiated. Furthermore, greater macroporosity of the base material also reduces the risk of pore clogging by the formed metal (hydr)oxide nanoparticle (Jain et al., 2013; Sandoval et al., 2011).

Presence of oxygen containing groups, such as carboxyl, carbonyl and hydroxyl groups, promotes creation of negative surface charges when a hybrid sorbent is exposed to $\mathrm{pH}$ environments of natural waters. These negative charges increase the energy requirements for sorption of weak-acid oxyanions, and consequently reduce the overall capacity of the hybrid media (Cooper et al., 2010). In contrast, a positive Donnan effect is frequently achieved when metal (hydr)oxide nanoparticles are impregnated inside the pores of strong base ion-exchange resin or porous media with high iso-electric point (Elton et al., 2013; Mitskevich et al., 2010; Pan et al., 2010; Sarkar et al., 2011). This is demonstrated in design of hydrous ferric oxide (HFO) based hybrid media where proper selection of support media greatly enhanced the arsenic removal performance due to Donnan effects. The presence of non-diffusing fixed positively charged amine groups in strong base ion-exchange resin (e.g. quaternary amines) has been utilized as a highly permeable interface for arsenate, thus influencing its sorption onto HFO particles embedded in the polymer phase (Cumbal and Sengupta, 2005). The strong base groups might partially neutralize the negative charge resulting from the metal (hydr)oxide low isoelectric points and reduce the energy required for sorption of weak-acid oxyanions. However, 
although infrequently published studies refer to the existence of these effects, systematic studies have not been conducted to describe and quantify the influence of these factors.

\subsection{Influence of sorbate/sorbent ratios on sorption thermodynamics}

Because monodentate complexes utilize only one Lewis acid sorption site instead of two, they consequently contribute to potentially higher sorption capacities in environments where material properties allow for simultaneous formation of both complexes, or meta-stable conditions that affect intra-particle surface diffusion (Badruzzaman et al., 2004; He et al., 2009; Pan and Liss, 1998a). This paradigm shift leads to reexamination of the theories suggesting that sorption capacity of a sorbent is constant and indirectly defined only by the sorbents' surface area (Pan and Liss, 1998b). In scenarios where multiple sorption configurations are possible between a sorbate and a sorbent, the sorbate concentration could seriously influence the innersphere complexation process and affect the sorption capacity of the sorbent (Fendorf et al., 1997). High sorbate/sorbent ratios lead to formation of the less thermodynamically stable monodentate inner-sphere complexes or outer-sphere complexes (Arai et al., 2001; Guana et al., 2008; Grossl et al., 1997; Otte et al., 2013). In contrast, low sorbate/sorbent ratios promote formation of bidentate complexes, especially in sorbents characterized with high surface areas (Fendorf et al., 1997, Zeng et al., 2008a). Although the stability of complexes is higher, it could lead to overall lower sorption capacities because more sorption sites are utilized by a lower number of sorbate oxyanions. Such treatment scenarios characterized by low sorbate/sorbent ratios are more realistic because most waters exhibit trace concentrations of toxic weak-acid oxyanions (Filella et al., 2002; Hernandez and Rodriguez, 2012; Smedley and Kinniburgh, 2002). Although unique groundwater matrices exist in some developing countries where the concentrations of toxic oxyanion contaminants exceed $1 \mathrm{mg} / \mathrm{L}$ (e.g. arsenic in Bangladesh), these represent infrequent exclusions rather than a general trend (Jiang et al., 2013). Interestingly, however, studies that describe and quantify this effect in terms of applicable knowledge are practically non-existent although it could be hypothesized that monodentate inner-sphere complexes are the predominant form under most realistic conditions testing and treatment conditions. For example, although some studies describe the density of Lewis acid sorption sites 
(Redman et al., 2002; Zhang et al., 2005), none of them describe the complexation dynamics and chemistry at different sorbate/sorbent ratios in context to practical sorbent applications.

Unrealistically selected sorbent/sorbate ratios (e.g. high sorbate concentration and very small dose of sorbent) lead to unrealistic results characterized by extremely high sorption capacities, which are incomparable with other results, useless, and inapplicable for designing actual real world treatment systems. Developing isotherm model descriptors is frequently a good approach to initially assess the sorption capacity of a sorbent for given conditions, which must be realistic if the data is to have any applicable value. Unsubstantiated selection and use isotherm models to fit data frequently does not contribute to providing real and practical insights into the sorption process under pseudo-equilibrium conditions; which are often incorrectly referred to as "equilibrium conditions". It is imperative to select isotherm models that describe as close as possible the experimental conditions. For example, frequently used Langmuir isotherm model assumes that adsorbent surface is made up of fixed individual sites with constant free-energy change where each site is capable of binding at most one molecule of sorbate (Foo and Hameed, 2010; Langmuir, 1917). In many cases, the basic assumption of the Langmuir model could not be fulfilled for arsenic and similar oxyanions under realistic conditions (unless special experimental constrains exist) because each "sorption site does not always bind one "molecule" of sorbate" or sorption occurs at different thermodynamic conditions (e.g. monodentate vs bidentate ligands). Freundlich isotherm model is probable the most applicable descriptor of sorption under pseudo-

equilibrium conditions because it provides latitude when addressing processes encompassing multi-layer sorption and heterogeneous distribution of sites with different adsorption energies; and the Freundlich intensity parameter $(1 / n)$ is an indirect indicator of the energy of sorption as summarized Equation 3.1 (Crittenden et al., 2005; Foo and Hameed, 2010; Freundlich, 1906). However, there is a pool of studies that indiscriminately use a battery of sorption models without providing solid reasoning and justification for their use, and consequently fall short on capitalizing on the wealth of practical information that these models offer (Jeppua and Clement, 2012; Kundu and Gupta, 2006; Nguyen et al., 2010; Shao et al., 2008).

\subsection{Influence of water matrix properties on sorption thermodynamic}


Sorption energy requirements are also governed by the $\mathrm{pH}$ induced oxyanion speciation in a water matrix. With increases in $\mathrm{pH}$, the electrostatic repulsion between the sorbent and sorbate amplifies because of oxyanion deprotonation (Liao et al., 2008; Myneni et al., 1997; Xi et al., 2010). The extent of this speciation at a given $\mathrm{pH}$ is governed by the weak-acid oxyanions' $\mathrm{pKa}$ values and $\mathrm{pH}$ of the environment. However, the increase in total concentration of negative charges, increases with the water matrix $\mathrm{pH}$ as a result of oxyanions' deprotonation (Fuller et al., 1993; Jordan et al., 2013b; Su et al., 2010). To a greater or lesser extent, pH induced deprotonation affects all weak-acid oxyanions in an aqueous solution. Many of these oxyanions are considered innocuous (e.g. carbonate, silicate, phosphate) and, as such, may not necessitate treatment. However, the similar chemistry of many innocuous weak-acid oxyanions actuates competition with their toxic counterparts for the same Lewis acid sorption sites (Bullough et al., 2010; Canecka et al., 2011; Dadwhal et al., 2011; Filella and Williams, 2002; Hsia et al., 1992a, 1992b; Jain and Loeppert, 2000; Leyva et al., 2001; Meng et al., 2000; McComb et al., 2007; Mustafa et al., 2008; Nakamaru and Sekine, 2008; Su et al., 2008, 2010; Zhu et al., 2011). For example, phosphate exhibits similar coordination chemistry and affinity for metal (hydr)oxides as arsenate and vanadate (Carabante at al., 2010; Chowdhury and Yanful, 2010; Darland and Inskeep, 1997; Jeong et al., 2007; Stachowicz et al. 2008; Torrent et al., 1990). By forming the same inner-sphere complexes, they effectively reduce sorbent's capacity for removing toxic oxyanions and potentially influence formation of less thermodynamically stable complexes. Although many metal (hydr)oxides exhibit low selectivity for many undesirable innocuous oxyanions, their sorption is promoted by their very high concentrations present in the water matrix (Bortun et al., 2010b; Frau et al., 2010; Hongshao and Stanforth, 2001; Hsia et al., 1994; Nguyen et al., 2011; Su and Puls, 2001; Wilkie and Hering, 1996; Zeng et al., 2008b). To illustrate, silica concentrations in groundwater matrices frequently exceed three orders of magnitude when compared to arsenic concentrations (Davis, 1964; Frey and Edwards, 1997). However, even at such high concentrations silica might not exhibit strong competition effect at $\mathrm{pH}<8$ because of its high $\mathrm{pK}_{\mathrm{a} 1}$ value $\left(\mathrm{pK}_{\mathrm{a} 1} \sim 9.65\right)$ (Iler, 1979). The competition effects exhibited by silica become significantly manifested at $\mathrm{pH}>8$ when significant portion of the silica becomes deprotonated and available for sorption (Möller and Sylvester, 2008; Xie et al., 2007). Consequently, the sorption capacity of the metal (hydr)oxide media and its removal performance is significantly reduced, resulting in higher operational costs. 
While the $\mathrm{pH}$ impacts on selectivity and sorption capacity are well understood, the possibility that metal (hydr)oxides' crystalline structures could be tailored to minimize the competition effect of silica and other similar competing oxyanions has not been investigated. There have been no systematic studies, however, that examine the factors governing complexation mechanisms of competing ions in context of maximizing sorbent's capacity for removal of weak-acid oxyanions from groundwater matrices.

\section{Factors governing the kinetic of sorption}

Understanding the mechanisms that control sorption kinetics is important for assessing the performance of sorbents for removal of weak-acid oxyanion contaminants. According to the two-film theory and pore-surface diffusion model (PSDM), sorption of weak-acid oxyanions by porous metal (hydr)oxides consists of four successive steps: (1) bulk diffusion; (2) external (film) diffusion; (3) intra-particle (internal) diffusion that occurs in via two mechanisms (a) pore diffusion and (b) surface diffusion; and (4) attachment on the solid surface (Figure 4) (Sperlich et al., 2005; Carter and Weber 1994; Crittenden et al., 1986a; Hand et al., 1997; Knappe et al. 1999; Weber and Chakravorty, 1974; Weber and Smith, 1987; Whitman, 1923; Xu et al., 2013; Zhang et al., 2009c). The first and the last steps are relatively fast when compared to the second and third step (Axe and Anderson, 1995; Axe and Trivedy, 2002). As such, the film and intra-particle mass transports represent the key factors that dictate the overall kinetics during sorption of an oxyanion contaminant (Crittenden et al. 1986b, 1987a; Hristovski et al., 2008a, 2008b, 2008c; Westerhoff et al., 2005). The extent of their influence is directly related to the properties of the (1) sorbent material, and (2) sorbate and water matrix properties (Crittenden et al., 2005; Garcia et al., 2017; Rosen, 1952; Yang et al., 2006; Zeng et al., 2008b; Zhang et al., 2005, 2008, 2010).

\section{$<$ Figure 4>}

\subsection{Influence of sorbent properties on sorption kinetic}

Both physical and chemical properties of a sorbent influence the overall intra-particle mass transport of an oxyanionic sorbate. To better understand how sorbent property factors 
influence the overall sorption kinetics, the relationships that describe both film and intra-particle mass diffusion have to be examined.

According to Ficks law, the film (external) diffusion flux of a sorbate (oxyanion/contaminant) $\left(J_{F}\right)$ is related to the free-liquid diffusivity of this sorbate $\left(D_{l}\right)$ and its concentration gradient through the stagnant film surrounding the sorbent particle as expressed via Equation (4.1):

$$
J_{F}=D_{l} \frac{\mathrm{d} C_{\text {Sorbate }}}{\mathrm{d} \delta_{\text {Film }}}
$$

For a steady-state concentration profile, which is expected under steady-state continuous configurations (i.e. packed/fixed bed systems), the film diffusion flux could be expressed in terms of a product between the film diffusion coefficient $\left(k_{f}\right)$ and the concentration difference between the bulk and sorbent's surface $(\Delta C)$ as given in (4.2):

$$
J_{F}=k_{f} \times \Delta C
$$

Consequently, in continuous-flow configurations in which the bulk concentration is relatively invariable, the film diffusion coefficient represents the key governing parameter that controls the film mass transport of the sorbate. This parameter is directly proportional to the Sherwood number $(S h)$ and the contaminants' free-liquid diffusivity $\left(D_{l}\right)$, while inverse proportional to the diameter of the sorbent particle $\left(d_{P}\right)$ as summarized in Equation (4.3).

$$
k_{f}=\frac{S h \times D_{l}}{d_{P}}
$$

The Sherwood number is a function of the Reynolds number (Re) (Equation 4.4) and Schmidt Number $(S c)$ (Equation 4.5) as expressed with the general relationship presented in expression (4.6):

$$
\begin{aligned}
& \operatorname{Re}=\frac{\rho_{l} \times \Phi \times d_{p} \times v_{f}}{\varepsilon_{F} \times \mu_{l}} \\
& S c=\frac{v}{D_{l}} \\
& S h=A+B \times \operatorname{Re}^{m} \times S c^{n}
\end{aligned}
$$

Where $A, B, m$, and $n$ are empirically derived constants based on operational ranges for the $R e$ and $S c$ numbers (Hristovski et al., 2008a, 2008b, 2008c; Sontheimer et al., 1988); $\rho_{l}$ and $\mu_{l}$ are 
the density and dynamic viscosity of water, respectively; $\Phi$ is the sphericity of the sorbent particle; $v_{f}$ and $\varepsilon_{F}$ are the superficial velocity and effective porosity of the continuous-flow configuration (bed void fraction), respectively.

For the most commonly used Gnielinski correlation, the empirically derived constant $A$ can be expressed as a function of $\varepsilon_{F}$ via Equation (4.7) (Hristovski et al., 2008a, 2008b, 2008c; Sontheimer et al., 1988):

$$
A=2 \times\left(1+1.5 \times\left(1-\varepsilon_{F}\right)\right)
$$

From Equations (4.1) to (4.7), it becomes evident that two particle morphology parameters control the film mass transport of oxyanionic contaminants: (1) particle size and (2) particle sphericity. According to (4.4) and (4.6), the particle size affects both the Reynolds and Sherwood numbers, which generally increase with increase in particle diameter under the same packed-bed operating conditions. Interestingly, the film diffusion coefficient is inversely proportional to the particle diameter, so the overall impact $d_{P}$ on $k_{f}$ would depend on the $S h / d_{p}$ ratio. Similarly, the particle shape, which is expressed in terms of particle sphericity, also affects the Reynolds number, and consequently, it impacts $k_{f}$.

The sorbent particle size also affects the two intra-particle diffusion mechanisms: (a) pore diffusion and (b) surface diffusion. The effect of particle size on pore diffusion coefficients $\left(D_{P}\right)$ is not initially evident from Equation (4.8), which is frequently used to estimate this dominant intra-particle mass transport mechanism.

$$
D_{P}=\frac{\varepsilon_{P} \times D_{l}}{\tau}
$$

Where $\tau$ is tortuosity, $\varepsilon_{P}$ is particle porosity and $D_{l}$ represent free liquid diffusivity of contaminant. However, as demonstrated by Crittenden et al. (1991), the pore diffusivity is dependent on the particle size as given by expression (4.9) (Westerhoff et al., 2005):

$$
\frac{D_{P-1}}{D_{P-2}}=\left(\frac{d_{P-1}}{d_{P-2}}\right)^{x}
$$

Where $D_{P-1}$ and $D_{P-2}$ are the pore diffusion coefficients corresponding to particle sizes $d_{P-1}$ and $d_{P-2}$, respectively.

Considering that $D_{l}$ of an oxyanion is constant for given temperature and viscosity conditions, it becomes obvious from Equations (4.8) and (4.9) that particle porosity and tortuosity are the key factors affecting the pore diffusion of this oxyanionic sorbate. This explanation aligns well with 
the rationale that the path of an oxyanionic sorbate becomes more tortuous as it diffuses deeper into the particle. In brief, larger particles provide for a longer route towards available sorption sites at the center of a sorbent, which typically yields to more "obstacles" and greater tortuosity for an oxyanion as it diffuses inside the sorbent pores. Consequently, the increased tortuosity slows down the sorbate's diffusion inside the sorbent particle pores.

With increase in particle porosity, the path of a sorbate diffusing through the sorbent's pores becomes less tortuous as summarized in Equation (4.10), which is useful for estimating tortuosity (Carter and Weber, 1994; LeVan et al., 1997). However, this bulk particle porosity parameter does not account for the pore size distribution and their morphology, which could be considered the two main factors determining tortuosity on a microscopic scale (Armatas, 2006; Garcia et al., 2017; Latour et al., 1995). In brief, two particles with same size, sphericity, and porosity may exhibit different tortuosites because of their different pore-size distributions and pore morphologies.

$$
\tau=\frac{\left(2-\varepsilon_{P}\right)^{2}}{\varepsilon_{P}}
$$

As the particle porosity decreases, pore diffusion coefficient is expected to also decrease as documented for organic anions (Garcia et al., 2017). This trend is especially evident if the cumulative volumes of macropore and mesopore regions are reduced because these two regions are the only ones comprised of pores that are large enough to permit unimpeded transport of hydrated oxyanions via this diffusion mechanism (Garcia et al., 2017; Saitua et al., 2011). Although larger micropores should not be excluded as contributors to this intraparticle mass transport mechanism, the $d_{\text {Micropore }} / d_{\text {anion }}$ is relatively small and unfavorable for oxyanions to permit their unimpeded pore diffusion even if electrostatic repulsion between the negatively charged oxyanions and sorbent surface favors this diffusive transport.

For micropores that are sufficiently large to permit intra-particle mass transport of oxyanions, surface diffusion could be expected to be the dominant mass transport mechanism because these pores are too small to nullify any interaction between the oxyanion and sorbent's surface. However, both macropores and mesopores may also contribute to surface diffusion of sorbates, especially if there is an electrostatic attraction between the negatively charged oxyanions and the positively charged surface. Although not as dominant as the pore diffusion, 
this mass transport mechanism could meaningfully contribute to the overall intrapartcile mass transport (Dale et al., 2016; Garcia et al., 2017; Medved and Cerny, 2011).

The surface diffusion contribution to the overall intraparticle mass transport depends on the thermodynamic stability of the formed complexes under different conditions, which in turn primarily depends on the sorbate and oxyanion sorbent chemistries. As discussed in Section 3, arsenic and similar oxyanions like to form inner-sphere complexes at available sorption sites on the surface of metal (hydr)oxide sorbents. These covalent bonds, which are characterized with Gibbs free energies changes of sorption frequently lower than $(-50) \mathrm{kJ} / \mathrm{mol}$, provide for very stable complexes that are difficult to break (Crittenden at al., 2005). Considering this high stability, it could be postulated that surface diffusion is rendered difficult if not for the intermediary and thermodynamically meta-stable states that exist during the sorption process (Farrell and Chaundhary, 2013; Pan and Liss, 1998a, 1998b). When the complexes are in these meta-stable states, significantly less energy is required to induce desorption of the sorbed oxyanions and cause their "tumbling" towards the next available sorption site as the pore surface diffusion model describes (Crittenden et al., 1986a, 1987b; Hand et al., 1984, 1989, 1997). Since the only available sites for sorption are towards the particle's center, the desorbed sorbate oxyanions could only move deeper into the sorbent as concentration gradient mandates. Temperature induced bond vibrations or other oxyanions trying to compete for the same sorption site are able to provide sufficient energy for desorption and consequent surface diffusion. However, as the oxyanions travel deeper into the particle, there are more favorable conditions to facilitate formation of stable inner-sphere complexes, which leads to slower surface diffusion mass transport. Consequently, as the particle size increases and it takes longer to reach the available sorption sites deeper into the sorbate particle, the surface diffusion decreases. Badruzzaman et al. (2004) documented this effect for sorption of arsenic onto granulated ferric hydroxide (GFH) by demonstrating increase in surface diffusion with decrease in particle size for the same experimental conditions. In contrast, the existence of sorption sites that exhibit different mechanism of sorption or lower affinity for arsenic-like oxyanions may promote their surface diffusion. As reported by Dale et al. (2016), less stable complexes are formed between the quaternary amine sites and arsenate in metal (hydr)oxide modified strong base ion-exchange resin, which enable nitrate to easily displace the arsenate and consequently promote its surface diffusion until the arsenate could form stable inner-sphere complexes. 
From the described mechanistic implications associated with surface diffusion of oxyanions onto metal (hydr)oxide surfaces, it could be postulated that increasing the number of potential sorption sites promotes both surface diffusion and sorption capacity, consequently creating a premise for fabricating sorbents with high surface area. While the high surface area of a sorbent particle plays an important role in surface diffusion and its sorption capacity, increase in the commonly reported overall Branuer-Emmet-Teller (BET) surface area does not necessarily promote surface diffusion (or overall sorption capacity) because not all BET determined surface area is available for the oxyanions to sorb. Many of the available sorption sites in the micropore region, which are available for $\mathrm{N}_{2}$ deposition during BET measurements, could be rendered unavailable due to pore size constrictions that prevent the larger oxyanions to access them. However, a recent study by Garcia et al. (2017) suggests that increase in surface area, especially in the mesopore and macropore regions, indeed has the potential to promote greater surface diffusivity in metal (hydr)oxide nano-enabled hybrid sorbents until significant pore clogging reverses the trend.

Unfortunately, only very small number of published studies address the implications of sorbent properties on sorption kinetics of oxyanions. Current research efforts are dominated by studies that focus on improving the capacity of sorbents, while the importance of kinetics is overlooked. This approach towards novel sorbent development has a deleterious effect on scaling up efforts, especially for small scale packed-bed systems (e.g. point-of-use or point-of-entrance systems), whose overall performance and design are frequently dominated by the contaminant mass transport mechanisms, and not by the sorption capacity of the media (Walker and Weatherley, 1997).

\subsection{Influence of sorbate and water matrix properties on sorption kinetic}

Oxyanion sorbate and water matrix properties represent another set of factors that influence the overall mass transport rates during sorption processes. Both physical and chemical properties of oxyanionic sorbates affect the interaction with sorbent surfaces and determine the extent of each diffusive mass transport mechanism. Examining these mass transport processes through the prism of sorbate and water matrix properties leads to better understanding of the mechanistic implications and development of improved sorbents for removal of oxyanions. 
According to the two-film theory and the PSDM, the temperature-dependent free liquid diffusivity $\left(D_{l}\right)$ represents the key governing factor that determines how fast oxyanions diffuse from the bulk into sorbent particles via film and pore diffusion mechanisms (Hayduk and Laudie, 1974; Hristovski et al. 2008a, 2008b, 2008c). Depending on water matrix chemistry and operating conditions of a sorption system, one of these mechanisms typically represents the rate limiting step for oxyanion contaminant mass transport at different stages of a sorbent exhaustion. However, the rates of both mechanisms are controlled by sorbate specie's free liquid diffusivity as summarized in Equations (4.3) and (4.8). The free liquid diffusivity is sorbate specific, and generally is related to its size and charge, with values ranging in the order of $10^{-5}-10^{-6} \mathrm{~cm}^{2} / \mathrm{s}$ for typical arsenic-like oxyanions (Lide, 2006). Weak-acid oxyanions with greater free liquid diffusivity values have an ability to move faster though the film surrounding the sorbent particle and inside its pores, which enables them to reach and occupy the available sorption sites sooner than their competition (Hristovski et al., 2008d; Sandoval et al., 2011). Consequently, the free liquid diffusivity creates a differentiating effect that could either amplify or impede preferential sorption of competitive oxyanions, which typically coexist in a water matrix. For oxyanions exhibiting lower concentrations, this diffusion induced effect could be easily ignored because of its negligible contribution. However, in presence of competing oxyanions with concentrations that are several orders of magnitude higher than the contaminants of interest, this effect could lead to a serious problem associated with decreased contaminant removal performance of the sorbent. Considering that the film diffusion flux is also dependent on the concentration gradient according to Equation (4.2), higher initial concentrations of competitive oxyanions leads to greater film flux resulting in competitive advantage of these oxyanions in accessing the pores or surfaces of the sorbent, even if their free liquid diffusivity $\left(D_{l}\right)$ is lower than the contaminants of interest. Silica is a typical example of non-toxic co-contaminant that exhibits a greater diffusivity and minimum two orders of magnitude higher concentrations in groundwaters than arsenic and similar oxyanions (Sandoval et al., 2011; Zeng et al., 2008b). Because at $\mathrm{pH}<7$, silica does not significantly deprotonate $(<0.1 \%)$, the amplified competition effect may not be significant because of low silicate ion concentrations (Iler, 1979; Jeong et al., 2007; Waltham and Eick, 2002). However, in groundwater with high $\mathrm{pH}$, this mass transport and concentration amplified competition has the potential to seriously impair the sorption capacity of media for removal of arsenic or similar weak-acid oxyanions. 
In contrast to the effects of $D_{l}$ on film and pore diffusion kinetics, high local concentrations of co-contaminants (e.g. silica) and their faster access into the pores of a metal (hydr)oxide sorbent may promote surface diffusion of already sorbed oxyanion contaminants (e.g. arsenic) that are in meta-stable states. In extreme scenarios (e.g. high pH and temperature), leaching of the sorbed oxyanion contaminants could occur as a result of desorption. Purposefully inducing extreme $\mathrm{pH}$ and temperature conditions, however, represents a common approach that is used to regenerate metal (hydr)oxide sorbents (Athanasaki et al., 2015; Farrell and Chaudhary, 2013; Guo and Chen, 2005; Sarkar et al., 2007).

With exception to studies related to $\mathrm{pH}$ effects on charge speciation of oxyanions, very little work has been done to elucidate and quantify the effects of sorbate chemistry onto mass transfer mechanism during sorption processes. Many studies do not consider these implications as sufficiently relevant when compared with sorption capacity properties. However, kinetics may be the controlling factor that determines the overall performance of a packed-bed sorbent system operated in either continuous or semi-continuous modes. The importance of this factor becomes especially evident in small point-of-use or point-of-entry systems, which are expected to capture the entire mass transfer zone when operated at high hydraulic loading rates and shorter empty bed contact times than their large-scale counterparts. This expectation could only be fulfilled by engineering inexpensive sorbents with morphologies that could minimize film and intra-particle mass transport limitations in addition to providing high sorption capacity and selectivity. Inadequately engineered sorbents frequently lead to inferior sorbent system designs, which typically translate into operational challenges, maintenance problems, and higher costs for many small communities.

\section{On sorbent fabrication and sorbent/sorbate/process characterization techniques}

To adhere to the rules of economics, which are primarily driven by the low cost of clean water, optimal sorbent fabrication processes must be relatively simple, inexpensive, and scalable to allow for rapid production of large quantities (Baig et al., 2015; Bundschuh et al., 2010; Farmen, 2015; Qu et al., 2013). Selection of sorbent synthesis methods and possibly toxic and expensive precursor materials, which frequently necessitate complex and high-priced fabrication equipment, typically render the newly engineered sorbents economically infeasible for 
commercialization (German et al., 2014). Because of these constraints, much of the existing work has been driven in the direction of fabricating inexpensive nanostructured metal (hydr)oxide sorbents or nano-enabled hybrids to facilitate high capacity and selectivity of weakacid oxyanion contaminants and co-contaminants (DeMarco et al., 2003; Hristovski et al., 2008d, 2009; Sarkar et al., 2011; Trujillo-Reyes at al., 2014). However, this pursuit to engineer novel sorbents has frequently overlooked factors that could significantly impact their employability in full-scale systems. For example, nanotizing metal (hydro)oxide sorbents or aggregating of nanomaterials could lead to reduced sorbent stability or porosity, increased attrition, or loss of surface area, which consequently creates operational problems such as head loss, channeling, or nanomaterial leaching into the treated effluent (Savage and Diallo, 2005; Sylvester et al., 2006). Although the leached metal (hydr)oxide nanomaterials may not pose environmental and health risks by themselves, they have the potential to concentrate oxyanions on their surface and increases the environmental and health risks associated with these oxyanionic contaminants (Sun et al., 2007). The notion of nanoparticles serving as vehicles to transport high concentrations oxyanionic contaminants indirectly raises concerns about environmental applications and implications of nanotechnology (Klaine et al., 2008; Maynard et al., 2006; Renn and Roco, 2006).

To minimize any risks and concerns associated with fabrication and use of novel sorbent technologies, it becomes imperative to properly characterize the fabricated sorbents and adequately quantify their performance and stability under extreme, but realistic, conditions. An array of analytical and characterization tools frequently needs to be employed to better describe, understand, and parameterize both the sorbents and the sorption processes. However, selection of appropriate tools has to be guided by two main criteria: (1) "Will the generated data provide answers to one or more research question that help prove a hypothesis?", and (2) "Are the employed analytical or characterization techniques and tools sufficiently sensitive and applicable for describing realistic conditions?" To illustrate the first criteria, a number of studies employ Fourier transform infrared spectroscopy (FTIR) or similar techniques to generate data, which do not provide any information that contributes to addressing a goal, a hypothesis, or a research question (Fan et al., 2012; Gupta et al., 2009; Yang et al., 2007). Similarly, to illustrate the second criteria, many studies describe experiments conducted under completely unrealistic conditions (e.g. batch sorption tests with arsenic concentration of $100 \mathrm{mg} / \mathrm{L}$ and sorbent dose of 
$0.1 \mathrm{~g} / \mathrm{L}$ ) because the only tool that was available for the study was an instrument that has a detection limit higher than $100 \mu \mathrm{g} / \mathrm{L}$ for example (Melamed, 2005). Consequently, the findings of such studies are rendered either irrelevant or unsuitable for addressing the overarching goal of engineering novel metal (hydr)oxide sorbents to remove weak-acid oxyanion contaminants from non-potable water sources.

\section{Conclusion}

In light of the gloomy predictions related to future water scarcity and pollution, which are especially expected to impact small communities relaying on groundwater as the only sources of potable water, point-of-use or point-of-entry water treatment systems might represent the best approach to mitigate the problems and address the challenges associated with clean drinking water. In many small communities, which lack financial, infrastructural, or technical resources to operate complex water treatment systems, sorbents may represent an ideal platform for engineering simple and inexpensive systems capable of simultaneously removing multiple harmful weak-acid oxyanions from complex water matrices.

Understanding the fundamental thermodynamics and kinetics mechanisms that control overall performance of sorption systems represents the first step in engineering novel sorbents that exhibit high capacity, selectivity, stability, durability and mass transport of contaminants under a wide range of operating and water matrix conditions. Neglecting the importance of one or more of these factors may lead to poor performance in realistic conditions or inability to employ the newly developed sorbent material in continuous-flow configurations although the laboratory scale tests may have demonstrated exemplary sorption capacity under pseudo-equilibrium. Consequently, current research to engineer the next generation of novel sorbents should exhibit a holistic approach, the performance testing and evaluation of the novel sorbents should be conducted under realistic conditions. Novel sorbents, which would not be able to comply with the purely driven economics factors of production scalability or cost expectations, are predestined to never be commercialized unless they exhibit extraordinary performances to offset any existing low cost stipulations.

\section{Acknowledgement}


This work was partially funded by the National Science Foundation through the Nano-Enabled Water Treatment (NEWT) Technologies Engineering Research Center (EEC-1449500) 


\section{References}

Ambe, S., 1987. Adsorption Kinetics of Antimony(V) Ions onto $\alpha-\mathrm{Fe}_{2} \mathrm{O}_{3}$ Surfaces from and Aqueous Solution. Langmuir 3, 489-493.

Arai, Y., Elzinga, E.J., Sparks, D.L., 2001. X-ray Absorption Spectroscopic Investigation of Arsenite and Arsenate Adsorption at the Aluminum Oxide-Water Interface. J. Colloid Interf. Sci. $235,80-88$.

Armatas, G.S., 2006. Determination of the effects of the pore size distribution and pore connectivity distribution on the pore tortuosity and diffusive transport in model porous networks. Chem. Eng. Sci. 61(14), 4662-4675

Athanasaki, G., Sherrill, L., Hristovski, K.D., 2015. The pore surface diffusion model as a tool for rapid screening of novel nanomaterial-enhanced hybrid ion-exchange media. Environ. Sci. Water Res. Technol. 1, 448-456.

Axe, L., Anderson, P.R., 1995. Sr Diffusion and Reaction within Fe Oxides: Evaluation of the Rate-Limiting Mechanism for Sorption. J. Colloid Interf. Sci. 175, 157-165.

Axe, L., Trivedi, P., 2002. Intraparticle surface diffusion of metal contaminants and their attenuation in microporous amorphous Al, Fe, and Mn oxides. J. Colloid Interf. Sci. 247(2), 259-265.

Badruzzaman, M., Westerhoff, P., Knappe, D.R.U., 2004. Intraparticle diffusion and adsorption of arsenate onto granular ferric hydroxide (GFH). Water Res. 38(18), 4002-4012.

Baig, S.A., Sheng,T., Hu Y., Xu, J., Xu, X., 2015. Arsenic Removal from Natural Water Using Low Cost Granulated Adsorbents: A Review. Clean - Soil, Air, Water 43(1), 13-26.

Banerjee, K., Amy, G.L., Prevost, M., Nour, S., Jekel, M., Gallagher, P.M., Blumenschein, C.D., 2008. Kinetic and thermodynamic aspects of adsorption of arsenic onto granular ferric hydroxide (GFH). Water Res. 42, 3371-3378.

Bang, S., Pena, M.E., Patel, M., Lippincott, L., Meng, X., Kim, K.W., 2011. Removal of arsenate from water by adsorbents: a comparative case study. Environ. Geochem. Hlth. 33, 133-141. 
Berg, P.A., 2015. The world's need for household water treatment. J. Am. Water Works Assoc. 107(10), 36-44.

Blake, R.L., Hessevick, R.E., 1966. Refinement of the hematite structure. Am. Mineral. 51, 123-129.

Bleiman, N., Mishael, Y.G., 2010. Selenium removal from drinking water by adsorption to chitosan-clay composites and oxides: Batch and columns tests. J. Hazard. Mater. 183, 590595.

Bogardi, J.J., Dudgeon, D., Lawford, R., Flinkerbusch, E., Meyn, A., Pahl-Wost, C., Vielhauer, K., Vörösmarty, C., 2012. Water security for a planet under pressure: interconnected challenges of a changing world call for sustainable solutions. Curr. Opin. Environ. Sustain. 4, 35-43.

Bondietti, G., Sinniger, J., Stumm, W., 1993. The reactivity of Fe(II1) (hydr)oxides: effects of ligands in inhibiting the dissolution. Colloid Surface A 79, 157-167.

Bortun, A., Bortun, M., Pardini, J., Khainakov, S.A., Garcia, J.R., 2010a. Synthesis and characterization of a mesoporous hydrous zirconium oxide used for arsenic removal from drinking water. Mater. Res. Bull. 45, 142-148.

Bortun, A., Bortun, M., Pardini, J., Khainakov, S.A., Garcia, J.R., 2010b. Effect of competitive ions on the arsenic removal by mesoporous hydrous zirconium oxide from drinking water. Mater. Res. Bull. 45, 1628-1634.

Bouwer, H., 2000. Integrated water management: emerging issues and challenges. Agr. Water Manage. 45, 217-228.

Brennan, R.T., McBean, E.A., 2011. The role of orthophosphate and dissolved oxygen in the performance of arsenic-iron removal plants in Bangladesh. J. Environ. Sci. Heal. A 46, 426435.

Breynaert, E., Bruggeman, C., Maes, A., 2008. XANES-EXAFS analysis of se solid-phase reaction products formed upon contacting Se(IV) with $\mathrm{FeS}_{2}$ and FeS. Envir. Sci. Technol. 42(10), 3591-3601. 
Bullough, F., Weiss, D.J., Dubbin, W., Coles, B.J., Barrott, J., SenGupta, A.K., 2010. Evidence of Competitive Adsorption of Sb(III) and As(III) on Activated Alumina. Ind. Eng. Chem. Res. 49(5), 2521-2524.

Bundschuh, J., Litter, M., Ciminelli, V.S.T., Morgada, M.E., Cornejo, L., Hoyos, S.G., Hoinkis, J., Alarcon-Herrera, M.T., Armienta, M.A., Bhattacharya, P., 2010. Emerging mitigation needs and sustainable options for solving the arsenic problems of rural and isolated urban areas in Latin America - A critical analysis. Water Res. 44, 5828-5845.

Camacho, L.M., Parra, R.R., Deng, S., 2011. Arsenic removal from groundwater by $\mathrm{MnO}_{2}$ modified natural clinoptilolite zeolite: Effects of $\mathrm{pH}$ and initial feed concentration. J. Hazard. Mater. 189, 286-293.

Canecka, L., Bujdos, M., Matus, P., 2011. Kinetic sorption study of arsenic, antimony, and phosphorous onto synthetic iron oxides. Fresen. Environ. Bull. 20(12A), 3401-04.

Carabante, I., Grahn, M., Holmgren, A., Hedlund, J., 2010. In situ ATR-FTIR studies on the competitive adsorption of arsenate and phosphate on ferrihydrite. J. Colloid Interf. Sci. 351, $523-31$.

Carter, M.C., Weber, W.J. 1994. Modeling adsorption of TCE by activated carbon preloaded by background organic matter. Environ. Sci. Technol., 28(4), 614-623.

Chang, Q., Lin, W., Ying, W., 2010. Preparation of iron-impregnated granular activated carbon for arsenic removal from drinking water. J. Hazard. Mater. 184, 515-22.

Chen, H., Jin, L., Wang, M., Xiao, D., Reisner, D., 2007. Reducing dissolution of $\mathrm{MnO}_{2}$ nanofibers by doping with ferric ion. Sci. Technol. Adv. Mat. 8, 63-66.

Chowdhury, S.R., Yanful, A.K., 2010. Arsenic and chromium removal by mixed magnetitemaghemite nanoparticlesand the effect of phosphate on removal. J. Environ. Manage. 91, 2238-2247.

Chowdhury, S.R., Yanful, E.K., Pratt, A.R., 2011. Arsenic removal from aqueous solutions by mixed magnetite-maghemite nanoparticles, Environ. Earth Sci. 64, 411-423. 
Cohen, D., Shamir, U., Sinai, G., 2004. Water Quality aspects of optimal operation of rural water distribution systems for supply of irrigation and drinking water. Irrig. Drain. 53, 339361.

Cooper, A.M., Hristovski, K.D., Moller, T., Westerhoff, P., 2010. The effect of carbon type on arsenic and trichloroethylene removal capabilities of iron (hydr)oxide nanoparticleimpregnated granulated activated carbons. J. Hazard. Mater. 183(1-3), 381-388.

Cornell, R.M., Schwerman, U., 2003. The Iron Oxides, Structure, Properties, Reactions, Occurrences and Uses, second ed. Willey-VCH GmbH \& Co. KGaA, Weinheim.

Crittenden, J.C., Berrigan, J.K., Hand, D.W., 1986b. Design of rapid small-scale adsorption tests for a constant diffusivity. J. Water Pollut. Control Fed., 58(4), 312-319.

Crittenden, J.C., Berrigan, J.K., Hand, D.W., Lykins, B., 1987a. Design of rapid fixed-bed adsorption tests for nonconstant diffusivities. J. Environ. Eng. 113, 243-259.

Crittenden, J.C., Hand, D.W., Arora, H., Lykins Jr., B.W., 1987b. Design Considerations for GAC Treatment of Organic Chemicals. J. Am. Water Works Assoc. 79(1), 74-82

Crittenden, J.C., Hutzler, N. J., Geyer, D. G., Oravitz, J. L., Friedman, G. 1986a. Transport of organic compounds with saturated groundwater flow: Model development and parameter sensitivity. Water Resour. Res. 22, 271-284.

Crittenden, J.C., Reddy, P.S., Arora, H., Trynoski, J., Hand, D.W., Perram, D.L., Summers, R.S., 1991. Predicting GAC Performance With Rapid Small-Scale Column Tests. J. Am. Water Works Assoc. 83(1), 77-87

Crittenden, J.C., Trussell, R.R., Hand, D.W., Howe, K.J., Tchobanoglous, G. (Eds.), 2005. Water Treatment: Principles and Design, second ed. Wiley \& Sons, Inc.: Hoboken, NJ.

Cumbal, L., Sengupta, A.K., 2005. Arsenic removal using polymer-supported hydrated iron(III) oxide nanoparticles: role of Donnan membrane effect, Envir. Sci. Technol. 39(17), 6508-6515.

Dadwhal, M., Sahimi, M., Tsotsis, T.T., 2011. Adsorption Isotherms of Arsenic on Conditioned Layered Double Hydroxides in the Presence of Various Competing Ions. Ind. Eng. Chem. Res. 50, 2220-2226. 
Dale, S., Markovski, J., Hristovski, K.D., 2016. Modeling packed bed sorbent systems with the Pore Surface Diffusion Model: Evidence of facilitated surface diffusion of arsenate in nano-metal (hydr)oxide hybrid ion exchange media. Sci. Total Environ. 563-564, 965-970.

Darland, J.E., Inskeep, W.P., 1997. Effects of $\mathrm{pH}$ and Phosphate Competition on the Transport of Arsenate. J. Environ. Qual. 26, 1133-1139.

Davis, S., 1964. Silica in Streams and groundwater. Am. J. Sci. 262, 870-891.

Davis, S.A., Mishra, M., 1997. Transport Model for the Adsorption of Oxyanions of Selenium (IV) and Arsenic (V) from Water onto Lanthanum and Aluminum-Based Oxides. J. Colloid Interf. Sci. 188, 340-50.

Dawoud, M.A., Raouf, A.R.A., 2009. Groundwater Exploration and Assessment in Rural Communities of Yobe State, Northern Nigeria. Water Reso. Manage. 23, 584-601.

Deliyanni, E., Bandsoszm, T.J., 2011. Importance of carbon surface chemistry in development of iron-carbon composite adsorbents for arsenate removal. J. Hazard. Mater. $186,667-674$.

DeMarco, M.J., Sengupta, A.K., Greenleaf, J.E., 2003. Arsenic removal using a polymeric/inorganic hybrid sorbent. Water Res. 37(1), 164-176.

Deng, S., Liu, H., Huang, J., Yu, G., 2010. Preparation, characterization and application of a Ce-Ti oxide adsorbent for enhanced removal of arsenate from water. J. Hazard. Mater. 179, 1010-1021.

Diamadopoulos, E., Ioannidis, S., Sakellaropoulos, G.P., 1993. As(V) removal from aqueous solutions by fly ash. Water Res. 27(12), 1773-1777.

Diebold, U., 2003. The surface science of titanium dioxide. Srf. Sci. Rep. 48, 53-229.

Dou, X., Zhang, Y., Zhao, B., Wu, X., Wu, Z., Yang, M., 2011. Arsenate adsorption on an Fe-Ce bimetal oxide adsorbent: EXAFS study and surface complexation modeling. Colloid Surface A 379, 109-15.

Duc, M., Lefèvre, G., Fédoroff, M., 2006. Sorption of selenite ions on hematite. J. Colloid Interf. Sci. 298, 556-63. 
Elton, J., Hristovski, K., Westerhoff, P., 2013. Titanium Dioxide base hybrid ion-exchange media for simultaneous removal of arsenic and nitrate, in: Ahuja, S., Hristovski, K., (Eds.), ACS Series 1123. American Chemical Society, Washington, pp. 223-236.

Fan, H.-T., Fan, X., Li, J., Guo, M., Zhang, D., Yan, F., Sun, T., 2012. Selective Removal of Arsenic(V) from Aqueous Solution Using A Surface-Ion-Imprinted Amine-Functionalized Silica Gel Sorbent, Ind. Eng. Chem. Res. 51, 5216-5223

Farmen, L.M., 2015. Arsenic removal metrics that commercialized the drinking water market, in: David E. Reisner, T. Pradeep (Eds.), Aquananotechnology: Global Prospects. CRC Press, Boca Raton, FL, USA, pp. 165-180.

Farrell, J., Chaudhary, B.K., 2013. Understanding Arsenate Reaction Kinetics with Ferric Hydroxides. Environ. Sci. Technol. 47, 8342-8347

Fendorf, S., Eick, M.J., Grossl, P., Sparks, D.L., 1997. Arsenate and chromate retention mechanisms on goethite. 1. Surface structure. Environ. Sci. Technol. 31(2), 315-320.

Filella, M., Belzile, N., Chen, Y.W., 2002. Antimony in the environment: a review focused on natural waters I. Occurrence. Earth Sci. Rev. 59, 125-176.

Filella, M., Williams, P.A., 2002. Antimony interactions with heterogeneous complexants in waters, sediments and soils: A review of binding data for homologous compounds. Chem. Erde. S4, 49-65.

Foo, K.Y., Hameed, B.H., 2010. Insights into the modeling of adsorption isotherm systems, Chem. Eng. J. 156, 2-10.

Foster, S.S.D, Chilton, P.J., 2003. Groundwater: the processes and global significance of aquifer degradation, Philos. T. Roy. Soc. B 358(1440), 1957-1972.

Frau, F., Addari, D., Atzei, D., Biddau, R., Cidu, R., Rossi, A., 2010. Influence of Major Anions on $\mathrm{As}(\mathrm{V})$ Adsorption by Synthetic 2-line Ferrihydrite. Kinetic Investigation and XPS Study of the Competitive Effect of Bicarbonate. Water Air Soil Poll. 205, 25-41.

Freundlich, H.M.F., 1906., Over the adsorption in solution, J. Phys. Chem. 57, 385-471.

Frey, M.M., Edwards, M.A., 1997. Surveying arsenic occurrence. J. Am. Water Works Assoc. 89(3), 105-117. 
Fuller, C.C., Davis, J.A., Waychunas, G.A., 1993. Surface chemistry of ferrihydrite: Part 2. Kinetics of arsenate adsorption and coprecipitation. Geochim. Cosmochim. Ac. 57, 22712282.

Gao, X., Wang, Y., Hu, Q., Su, C., 2011. Effects of anion competitive adsorption on arsenic enrichment in groundwater. J. Environ. Sci. Heal. A 46, 471-479.

Garcia, J., Markovski, J., McKay Gifford, J., Apul, O., Hristovski, K.D., 2017. The effect of metal (hydr)oxide nano-enabling on intraparticle mass transport of organic contaminants in hybrid granular activated carbon, Sci. Total Environ. 586, 1219-1227.

Gaskov, A., Rumyantseva, M., 2008. Metal Oxide Nanocomposites: Synthesis and Characterization in relation to Gas Sensing Phenomena, in: Baraton, M.I., (Ed.), Proceedings of the NATO Advanced Study Institute on Sensors for Environment, Health and Security: Advanced Materials and Technologies. Springer, Dordecht, The Netherlands, pp. 3-30.

German, M., Seingheng, H., SenGupta, A.K., 2014. Mitigating arsenic crisis in the developing world: Role of robust, reusable and selective hybrid anion exchanger (HAIX), Sci. Total Environ. 488-489, 547-553.

Gibbons, M.K., Gagnon, G.A., 2011. Understanding removal of phosphate or arsenate onto water treatment residua solids. J. Hazard. Mater. 186, 1916-1923.

Goh, K.H., Lim, T.T., 2004. Geochemistry of inorganic arsenic and selenium in a tropical soil: effect of reaction time, $\mathrm{pH}$, and competitive anions on arsenic and selenium adsorption. Chemosphere 55, 849-859.

Goldberg, S., Johnston, C.T., 2001. Mechanisms of arsenic adsorption on amorphous oxides evaluated using macroscopic measurements, vibrational spectroscopy, and surface complexation modeling. J. Colloid Interf. Sci. 234, 204-216.

Gorny, J., Billon, G., Lesven, L., Dumoulin, D., Madé, B., Noiriel, C., 2015. Arsenic behavior in river sediments under redox gradient: a review. Sci. Total Environ. 505, 423-434.

Greenwood, N.N., Earnshaw, A., 1998. Chemistry of the Elements, second ed. ButterworthHeinemann, Linacre House, Jordan Hill, Oxford, UK. 
Grossl, P.R., Eick, M., Sparks, D., Goldberg, S., Ainsworth, C.C., 1997. Arsenate and chromate retention mechanisms on goethite. 2. Kinetic evaluation using a pressure-jump relaxation technique. Environ. Sci. Technol. 31, 321-326.

Guana, X.-H., Wang, J., Chusuei, C.C., 2008. Removal of arsenic from water using granular ferric hydroxide: Macroscopic and microscopic studies. J. Hazard. Mater. 156, 178-185

Guo, X., Chen, F., 2005. Removal of Arsenic by Bead, Cellulose Loaded with Iron Oxyhydroxide from Groundwater. Environ. Sci. Technol. 39, 6808-6818.

Gupta K., Basu T., Ghosh U.C., 2009. Sorption Characteristics of Arsenic(V) for Removal from Water Using Agglomerated Nanostructure Iron(III)-Zirconium(IV) Bimetal Mixed Oxide, J. Chem. Eng. Data 54, 2222-2228.

Gupta, K., Ghosh, U.C., 2009. Arsenic removal using hydrous nanostructure iron(III)titanium(IV) binary mixed oxide from aqueous solution, J. Hazard. Mater. 161, 884-892.

Halsey, G., Taylor, H.S., 1947. The Adsorption of Hydrogen on Tungsten Powders. J. Chem. Phys. 15, 624-630.

Han, D.S., Abdel-Wahab, A., Batchelor, B., 2010. Surface complexation modeling of arsenic(III) and arsenic(V) adsorption onto nanoporous titania adsorbents (NTAs). J. Colloid Interf. Sci. 348, 591-599.

Hana, J., Leeb, S., Choic, K., Kim, J., Ha, D., Lee, C.-G., An, B., Lee, S.-H., Mizuseki, H., Choi, J.-W., Kang, S., 2016. Effect of nitrogen doping on titanium carbonitride-derived adsorbents used for arsenic removal. J. Hazard. Mater. 302, 375-385.

Hand, D., Crittenden, J., Thacker, W.E., 1984. Simplified models for design of fixed-bed adsorption systems, J. Environ. Eng. 110, 440-456.

Hand, D.W., Crittenden, J.C., Arora, H., Miller, J.M., Lykins Jr., B.W., 1989. Designing Fixed-Bed Adsorbers to Remove Mixtures of Organics, J. Am. Water Works Assoc. 81(1), $67-77$.

Hand, D.W., Crittenden, J.C., Hokanson, D.R., Bulloch, J.L. 1997. Predicting the performance of fixed-bed granular activated carbon adsorbers. Water Sci. Technol. 35, 235241. 
Hayduk, W., Laudie, H., 1974. Prediction of diffusion coefficients for nonelectrolytes in dilute aqueous solutions. AIChE J. 20, 611-619.

He, G.Z., Pan, G., Zhang, M.Y., Wu, Z.Y., 2009. Quantitative XANES Studies on Metastable Equilibrium Adsorption of Arsenate on $\mathrm{TiO}_{2}$ Surfaces. J. Phys. Chem. C 113(39), 17076-17081.

Helweg, O.J., 2000. Water for a growing population - Water supply and groundwater issues in developing countries. Water Int. 25, 33-39.

Hernandez, H., Rodriguez, R., 2012. Geochemical evidence for the origin of vanadium in an urban environment. Environ. Monit. Assess. 184, 5327-5342.

Hodi, M., Potyak, K., Hlavay, J., 1995. Removal of pollutants from drinking water by combined ion-exchange and adsorption methods. Environ. Int. 21(3), 325-331.

Hoekstra, A.Y., Mekonnen, M.M., 2011. Global water scarcity: monthly blue water footprint compared to blue water availability for the world's major river basins. Value of Water Research Report Series No. 53. UNESCO-IHE, Delft, the Netherlands.

Hong, H.J., Farooq, W., Yang, J.S., Yang, J.W., 2010. Preparation and Evaluation of Fe-Al Binary Oxide for Arsenic Removal: Comparative Study with Single Metal Oxides. Sep. Sci. Technol. 45(12), 1975-1981.

Hongshao Z., Stanforth R., 2001. Competitive Adsorption of Phosphate and Arsenate on Goethite. Environ. Sci. Technol. 35, 4753-4757.

Hristovski, K., Baumgardner, A., Westerhoff, P., 2007. Selecting metal oxide nanomaterials for arsenic removal in fixed bed columns: From nanopowders to aggregated nanoparticle media. J. Hazard. Mater. 147, 265-274.

Hristovski, K., Nguyen, H., Westerhoff, P.K., 2009. Removal of arsenate and 17a-ethinyl estradiol (EE2) by iron (hydr)oxide modified activated carbon fibers. J. Environ. Sci. Heal. A 44(4), 354-361.

Hristovski, K., Westerhoff, P., Crittenden, J., 2008a. An Approach for Evaluating Nanomaterials for use as a Packed Bed Adsorber Media: A Case Study of Arsenate Removal by Titanate Nanofibers. J. Hazard. Mater. 156(1-3), 604-611. 
Hristovski, K., Westerhoff, P., Crittenden, J., Olson, L., 2008b. Arsenate Removal by Nanostructured $\mathrm{ZrO}_{2}$ Spheres. Environ. Sci. Technol. 42, 3786-3790.

Hristovski, K., Westerhoff, P., Möller, T., Sylvester, P., Condit, W., Mash, H., 2008d. Simultaneous removal of perchlorate and arsenate by ion-exchange media modified with nanostructured iron (hydr)oxide. J. Hazard. Mater. 152, 397-406.

Hristovski, K.D., Westerhoff, P.K., Crittenden, J.C., Olson, L.W., 2008c. Arsenate removal by iron (hydr)oxide modified granulated activated carbon: Modeling arsenate breakthrough with the pore surface diffusion model. Sep. Sci. Technol. 43(11-12), 3154-67

Hristovski, K.D., Westerhoff, P.K., Moller, T., Sylvester, P., 2009. Effect of synthesis conditions on nano-iron (hydr)oxide impregnated granulated activated carbon. Chem. Eng. J. 146(2), 237-43.

Hsia, T.H., Lo, S.L., Lin, C.F., 1992a. As(V) adsorption on amorphous iron-oxide - triple layer modeling, Chemosphere 25(12), 1825-1837.

Hsia, T.H., Lo, S.L., Lin, C.F., 1992b. Interactions of $\mathrm{Cr}(\mathrm{VI})$ with amorphous iron-oxide adsorption density and surface charge. Water Sci. Technol. 26(1-2), 181-189.

Hsia, T.H., Lo, S.L., Lin, C.F., Lee, D.Y., 1994. Characterization of arsenate adsorption on hydrous iron oxide using chemical and physical methods. Colloid. Surface. A 85(1), 1-7.

Iler, K.R., 1979. The chemistry of silica: solubility, polymerization, colloid and surface properties, and biochemistry. John Wiley \& Sons, New York.

Ippolito, J.A., Barbarick, K.A., Elliot, H.A., 2011. Drinking Water Treatment Residuals: A Review of Recent Uses. J. Environ. Qual. 40, 1-2.

Ippolito, J.A., Scheckel, K.G., Barbarick, K.A., 2009. Selenium adsorption to aluminumbased water treatment residual. J. Colloid Interf. Sci. 338, 48-55.

Jain, A., Loeppert, R.H., 2000. Effect of competing anions on the adsorption of arsenate and arsenite by ferrihydrite. J. Environ. Qual. 29, 1422-1430.

Jain, A., Raven, K.P., Loeppert, R.H., 1999. Arsenite and Arsenate Adsorption on Ferrihydrite: Surface Charge Reduction and Net OH- Release Stoichiometry. Environ. Sci. Technol. 33, 1179-1184. 
Jain, A., Sanner, J., Sandoval, R., Hristovski, K., 2013. Hematite Nanoparticle Modified Granular Activated Carbon for Removal of Arsenic and Organic Co-Contaminants, in: Ahuja, S., Hristovski, K., (Eds.), ACS Series1123, Washington, pp. 206-222.

Jegadeesan, G., Al-Abed, S.R., Sundaram, V., Choi, H., Scheckel, K.G., Dionysiou, D.D., 2010. Arsenic sorption on $\mathrm{TiO}_{2}$ nanoparticles: Size and crystallinity effects. Water Res. 44, 965-973.

Jeong, Y., Maohong, F., Leeuwen, J.V., Belczyk, J.F., 2007. Effect of competing solutes on $\operatorname{arsenic}(\mathrm{V})$ adsorption using iron and aluminum oxides. J. Environ. Sci. 19, 910-919

Jeppua, G.P., Clement, T.P., 2012. A modified Langmuir-Freundlich isotherm model for simulating pH-dependent adsorption effects. J. Contam. Hydrol. 129-130, 46-53

Jiang, J.Q., Ashekuzzaman, S.M., Jiang, A., Sharifuzzaman, S.M., Chowdhury, S.R., 2013. Arsenic Contaminated Groundwater and Its Treatment Options in Bangladesh. Int. J. Env. Res. Pub. He. 10, 18-46.

Jin, J., Ma, X., Kim, C.Y., Ellis, D.E., Bedzyk, M.J., 2007. Adsorption of V on a hematite (0001) surface and its oxidation: Monolayer Coverage. Surf. Sci. 601, 4571-4581.

Johnston, C.P., Chrysochoou, M., 2016. Mechanisms of Chromate, Selenate, and Sulfate Adsorption on Al-Substituted Ferrihydrite: Implications for Ferrihydrite Surface Structure and Reactivity, Environ. Sci. Technol. 50, 3589-3596

Jordan, N., Ritter, A., Foerstendorf, H., Scheinost, A.C., Weißa, S., Heima, K., Grenzer, J., Mucklichc, A., Reuther, H., 2013a. Adsorption mechanism of selenium(VI) onto maghemite. Geochim. Cosmochim. Ac. 103, 63-75.

Jordan, N., Müller, K., Franzen, C., Brendler, V., 2013b. Temperature impact on the sorption of selenium(VI) onto anatase. J. Colloid. Interf. Sci. 390, 170-175.

Kamei-Ishikawa, N., Nakamaru, Y., Tagami, K., Uchida, S., 2008. Sorption behavior of selenium on humic acid under increasing selenium concentration or increasing solid/liquid ratio. J. Environ. Radioactiv. 99, 993-1002.

Kataoka, T, Dumesic, J.A., 1988. Acidity of unsupported and silica-supported vanadia, molybdena, and titania as studied by pyridine adsorption. J. Catal. 112, 66-79. 
Klaine, S.J., Alvarez, P.J.J., Batley, G.E., Fernandes, T.F., Handy, R.D., Lyon, D.Y., Mahendra, S., Mclaughlin, M.J., Lead, J.R., 2008. Nanomaterials in the environment: Behavior, fate, bioavailability, and effects. Environ. Toxicol. Chem. 27(9), 1825-1851.

Knappe, D.R.U., Snoeyink, V.L., Roche, P., Prados, M.J., Bourbigot, M.M. 1999. Atrazine removal by preloaded GAC. J. Am. Water Works Assoc. 91(10), 97-109.

Kosmulski, M., 2002, The significance of the difference in the point of zero charge between rutile and anatase. Adv. Colloid Interfac. 99, 255-264.

Kosmulski, M., Maczka, E., Jartych, E., Rosenholm, J.B., 2003. Synthesis and characterization of goethite and goethite-hematite composite: experimental study and literature survey. Adv. Colloid Interfac. 103, 57-76.

Kundu, S., Gupta, A.K., 2006. Arsenic adsorption onto iron oxide-coated cement (IOCC): Regression analysis of equilibrium data with several isotherm models and their optimization, Chem. Eng. J. 122, 93-106.

Kutzelnigg, W., 1984. Chemical Bonding in higher main group elements. Angew. Chem. Int. Edit. 23(4), 272-295.

Lange, F., Schmelz, H., Knozinger, H., 1991. An X-ray photoelectron spectroscopy study of oxides of arsenic supported on $\mathrm{TiO}_{2}$. J. Electron Spectrosc. 57, 307-315.

Langmuir, I., 1917. The constitution and fundamental properties of solids and liquids. J. Franklin I. 183(1), 102-105

Latour, L.L., Kleinberg, R.L., Mitra, P.P., Sotak, C.H., 1995. Pore-size distributions and tortuosity in heterogeneous porous media. J. Magn. Reson. Ser. A, 112, 83-91.

LeMire, L.E., Teixeira, M.A., Reed, B.E., 2010. Removal of As(V) using an Ironimpregnated Ion Exchange Bead. Sep. Sci. Technol. 45, 2051-2063.

LeVan, D.M., Carta, G., Yon, C.M., 1997. Chapter 16, Adsorption and Ion Exchange, In Perry's Chemical Engineers' Handbook, $7^{\text {th }}$ ed.; Perry, R. D., Green D. W., Eds.; McGrawHill: New York.

Leyva, A.G., Marrero, J., Smichowski, P., Cicerone, D., 2001. Sorption of Antimony onto Hydroxyapatite. Environ. Sci. Technol. 35, 3669-3675. 
Li, X., Dou, X., Li, J., 2012. Antimony(V) removal from water by iron-zirconium bimetal oxide: Performance and mechanism. J. Environ. Sci.-China 24(7), 1197-11203.

Li, Z., Jean, J., Jiang, W., Chang, P., Chen, C., Liao, L., 2011. Removal of arsenic from water using Fe-Exchanged natural zeolite. J. Hazard. Mater. 187, 318-323.

Liao, X.P., Tang, W., Zhou, R.Q., Shi, B., 2008. Adsorption of metal anions of vanadium(V) and chromium(VI) on $\mathrm{Zr}(\mathrm{IV})$-impregnated collagen fiber. Adsorption 14, 55-64.

Lide, D., (Ed.), 2006. CRC Handbook of Chemistry and Physics, 87th ed. Taylor and Francis Group: Boca Raton, FL.

Litter, M.I., Alarcón-Herrera, M.T., Arenas, M.J., Armienta, M.A., Cáceres, R.E., Cipriani, H.N., et al., 2012. Small-scale and household methods to remove arsenic from water for drinking purposes in Latin America. Sci. Total Environ. 429, 107-122.

Liu, H., Deng, S., Li, Z., Yu, G., Huang, J. 2010. Preparation of Al-Ce hybrid adsorbent and its application for defluoridation of drinking water. J. Hazard. Mater. 179, 424-430.

Liu, Y., 2009. Is the free Energy Change of Adsorption Correctly Calculated? J. Chem. Eng. Data 54, 1981-1985.

Ma, L., Tu, S.X., 2011. Removal of arsenic from aqueous solution by two types of nano $\mathrm{TiO}_{2}$ crystals, Environ. Chem. Lett. 9, 465-472.

Maeda, S., Ohki, A., Tsurusaki, Y., Takesjita, T., 1990. Selective adsorption of arsenic (V) by used of iron (III) hydroxide-loaded coral limestone. Sep. Sci. Technol. 25(5), 547-555.

Maji, S.K., Kao, Y.-H., Liu, C.-W., 2011. Arsenic removal from real arsenic-bearing groundwater by adsorption on iron-oxide-coated natural rock (IOCNR). Desalination 280, $72-79$.

Majzlan, J., 2010. Thermodynamic Stabilization of Hydrous Ferric Oxide by Adsorption of Phosphate and Arsenate. Environ. Sci. Technol. 45, 4726- 32.

Manceau, A., 1995. The mechanism of anion adsorption on iron oxides: Evidence for the bonding of arsenate tetrahedra on free $\mathrm{Fe}(\mathrm{O}, \mathrm{OH})_{6}$ edges. Geochim. Cosmochim. Ac. 59(17), 3647-3653. 
Manceau, A., Charlet. L., 1994. The mechanism of selenate adsorption on goethite and hydrous ferric oxide. J. Colloid Interf. Sci. 168, 87-93.

Manning, B., Fendorf, S., Bostick, B., Suarez, D., 2002. Arsenic(III) oxidation and arsenic(V) adsorption reactions on synthetic birnessite. Environ. Sci. Technol. 36 (5), 976981.

Mariussen, E., Ljønes, M., Strømseng, A.E., 2012. Use of sorbents for purification of lead, copper and antimony in runoff water from small arms shooting ranges. J. Hazard. Mater. 243, 95-104.

Maynard, D., Aitken, R. J., Butz, T., Colvin, V., Donaldson, K., Oberdörster, G., Philbert, M. A., Ryan, J., Seaton, A., Stone, V., Tinkle, S. S., Tran, L., Walker, N. J., Warheit, D. B., 2006. Safe handling of nanotechnology, Nature 267-269.

McComb, K.A., Craw, D., McQuillan, J.A., 2007. ATR-IR Spectroscopic Study of Antimonate Adsorption to Iron Oxide. Langmuir 23, 12125-12130.

Medved, I., Cerny, R., 2011. Surface diffusion in porous media: a critical review. Micropor. Mesopor. Mat. 142, 405-422.

Melamed, D., 2005. Monitoring arsenic in the environment: a review of science and technologies with the potential for field measurements. Anal. Chim. Acta 532, 1-13.

Meng, X.G., Bang, S.B., Korfiatis, G.P., 2000. Effects of silicate, sulfate, and carbonate on arsenic removal by ferric chloride. Water Res. 34, 1255-1261.

Mitskevich, D.E., Soldatov, V.S., Sokol, V.P., Vecher, E.I., 2010. Oxidant-Sorbent System for Potable Water Purification to Remove As(III) and As(V) Oxyanions. Russ. J. App. Chem. 83(3), 414-419.

Mitsunobu, S., Takahashi, Y., Sakai, Y., Inumaru, K., 2009. Interaction of Synthetic Sulfate Green Rust with Antimony(V). Environ. Sci. Technol. 43(2), 318-323.

Mitsunobu, S., Takahashi, Y., Terada, Y., Sakata, M., 2010. Antimony(V) Incorporation into Synthetic Ferrihydrite, Goethite, and Natural Iron Oxyhydroxides. Environ. Sci. Technol. 44(10), 3712-3718. 
Mohan, D., Pittman, C.U., 2007. Arsenic removal from water/wastewater using adsorbents-A critical review. J. Hazard. Mater. 142, 1-53.

Möller, T., 2011. Field pilot evaluations of iron oxide-based arsenic adsorption media, J. Am. Water Works Assoc. 103(1), 93-102.

Möller, T., Sylvester, P., 2008. Effect of silica and pH on arsenic uptake by resin/iron oxide hybrid media. Water Res. 42, 1760-1766.

Monteil-Rivera, F., Fedoroff, M., Jeanjean, J., Minel, L., Barthes, M.G., Dumonceau, J., 2000. Sorption of Selenite on Hydroxyapatite: An Exchange Process. J. Colloid Interf. Sci. 221, 291-300.

Mostafa, M.G., Chen, Y., Jean, J., Liu, C., Lee, Y., 2011. Kinetics and mechanism of arsenate removal by nanosized iron-oxide perlite. J. Hazard. Mater. 187, 89-95.

Mou, F., Guan, J., Xiao, Z., Sun, Z., Shi, W., Fan, X., 2011. Solvent-mediated synthesis of magnetic $\mathrm{Fe}_{2} \mathrm{O}_{3}$ chestnut-like amorphous-core $/ \gamma$-phase-shell hierarchical nanostructures with strong As(V) removal capability. J. Mater. Chem. 21, 5414-5421.

Müller, K., Ciminelli, V.S.T., Dantas, M.S.S., Willscher, S., 2010. A comparative study of $\mathrm{As}(\mathrm{III})$ and $\mathrm{As}(\mathrm{V})$ in aqueous solutions and adsorbed on iron oxy-hydroxides by Raman spectroscopy. Water Res. 44, 5660-5672.

Mustafa, S., Khan, S., Zaman, M.I., 2010. Effect of $\mathrm{Ni}^{2+}$ ion doping on the physical characteristics and chromate adsorption behavior of goethite. Water Res. 44, 918-926.

Mustafa, S., Zaman, M.I., Khan, S., 2008. Temperature effect on the mechanism of phosphate anions sorption by $\beta-\mathrm{MnO}_{2}$. Chem. Eng. J. 141, 51-57.

Mutikanga, H.E., Sharma, S., Vairavamoorthy, K., 2009. Water loss management in developing countries: Challenges and prospects. J. Am. Water Works Assoc. 101(12), 5768.

Myneni, S.B., Traina, S.J., Logan, T.J., Waychunas, G.A., 1997. Oxyanion Behavior in Alkaline Environments: Sorption and Desorption of Arsenate in Ettringite. Environ. Sci. Technol. 31, 1761-1768. 
Naeem, A., Westerhoff, P., Mustafa, P., 2007. Vanadium removal by metal (hydr)oxide adsorbents. Water Res. 41(7), 1596-1602.

Nakamaru, Y., Sekine, K., 2008. Sorption behavior of selenium and antimony in soils as a function of phosphate ion concentration. Soil Sci. Plant Nutr. 54, 332-341.

Nguyen, T.V., Vigneswaran, S., Ngo, H.H., Kandasamy, J., 2010. Arsenic removal by iron oxide coated sponge: Experimental performance and mathematical models. J. Hazard. Mater. $182,723-729$

Nguyen, V.L., Chen, W.H., Young, T., Darby, J., 2011. Effect of interferences on the breakthrough of arsenic: Rapid small scale column tests. Water Res. 45, 4069-4080.

Nilchi, A., Garmarodi, R.S., Darzi, J., 2011. Removal of Arsenic from Aqueous Solutions by an Adsorption Process with Titania-Silica Binary Oxide Nanoparticle Loaded Polyacrylonitrile Polymer. J. Poly. Sc. 119, 3495-3503.

Nordstrom, D.K., Archer, D.G., 2003. Arsenic thermodynamic data and environmental geochemistry, in: Welch, A.H., Stollenwerk, K.G. (Eds.), Arsenic in Ground Water. Springer US, pp. 1-25.

Otte, K., Schmahl, W.W., Pentcheva, R., 2013. DFT+U Study of Arsenate Adsorption on FeOOH surfaces: Evidence for Competiting Binding Mechanisms. J. Phys. Chem. 117, 15571-15582.

Pan, B., Lili Xiao, L., Nie, G., Pan, B., Wu, J., Lv, L., Zhanga, W., Zheng, S., 2010. Adsorptive selenite removal from water using a nano-hydrated ferric oxides (HFOs)/polymer hybrid adsorbent. J. Environ. Monitor. 12, 305-310.

Pan, G., Liss, P.S., 1998a. Metastable-equilibrium adsorption theory - I. Theoretical. J. Colloid Interf. Sci. 201(1), 71-76.

Pan, G., Liss, P.S., 1998b. Metastable-equilibrium adsorption theory - II. Experimental. J. Colloid Interf. Sci. 201(1), 77-85.

Park, H., Myung, N.V., Jung, H., Choi, H., 2009. As(V) remediation using electrochemically synthesized maghemite nanoparticles. J. Nanopart. Res. 11, 1981-1989 
Park, J., Kim, J., 2011. Characterization of Adsorbed arsenate on amorphous and nanocrystaline MgFe-Layered double hydroxides. J. Nanopart. Res. 13, 887-894.

Peacock, C.L., Sherman, D.M., 2004. Vanadium(V) adsorption onto goethite (alpha-FeOOH) at $\mathrm{pH} 1.5$ to 12: A surface complexation model based on ab initio molecular geometries and EXAFS spectroscopy. Geochim. Cosmochim. Ac. 68(8), 1723-1773.

Peak, D., 2006. Adsorption mechanisms of selenium oxyanions at the aluminum oxide/water interface. J. Colloid Interf. Sci. 303(2), 337-345.

Peraniemi, S., Hannonen, S., Mustalahti, H., Ahlgren, M., 1994. Zirconium loaded activated charcoal as an adsorbent for arsenic, selenium and mercury. Fresen. J. Analytical. Chem. $349,510-515$.

Pierce, M.L., Moore, C.B., 1980. Adsorption of arsenite on amorphous iron hydroxide from dilute aqueous solutions. Environ. Sci. Technol. 14(2), 214-216.

Pierce, M.L., Moore, C.B., 1982. Adsorption of arsenite and arsenate on amorphous iron hydroxide. Water Res. 16(7), 1247-1253.

Pillewan, P., Mukherjee, S., Roychowdhury, T., Das, S., Bansiwal, A., Rayalu, S., 2011. Removal of $\mathrm{As}(\mathrm{III})$ and $\mathrm{As}(\mathrm{V})$ from water by copper oxide incorporated mesoporous alumina. J. Hazard. Mater. 186, 367-375.

Pirilä, M., Martikainen, M., Ainassaari, K., Kuokkanen, T., Keiski, R.L., 2011. Removal of aqueous As(III) and As(V) by hydrous titanium dioxide, J. Colloid Interf. Sci. 353, 257-262.

Prathap, K., Namasivayam, C., 2010. Adsorption of vanadate(V) on Fe(III)/Cr(III) hydroxide waste. Environ. Chem. Lett. 8, 363-371.

Qu, X., Alvarez, P.J.J., Li, Q., 2013. Applications of nanotechnology in water and wastewater treatment. Water Res. 47, 3931-3946.

Rakshit, D., Sarkar, D., Punamiyaa, P., Datta, R., 2011. Antimony sorption at gibbsite-water interface. Chemosphere 84, 480-483.

Ramana, A., Sengupta, A., 1992. Removing Selenium (IV) and Arsenic (V) oxyanions with tailored chelating polymers. J. Environ. Eng. 118(5), 755-775. 
Ravenscroft, P., Brammer, H., Richards, K., 2009. Arsenic Pollution: a Global Synthesis. John Wiley \& Sons, New York, USA.

Redman, A.D., Macalady, D.L., Ahmann, D., 2002. Natural Organic Matter Affects Arsenic Speciation and Sorption onto Hematite. Environ. Sci. Technol. 36, 2889-2896.

Ren, Z., Zhang, G., Chen, J.P., 2011. Adsorptive removal of arsenic from water by an ironzirconium binary oxide adsorbent. J. Colloid Interf. Sci. 353, 230-237.

Renn, O., Roco, M.C., 2006. Nanotechnology and the need for risk governance. J. Nanopart. Res. 8, 153-191.

Rosen, J.B., 1952. Kinetics of a Fixed Bed System for Solid Diffusion into Spherical Particles, The Journal of Chemical Physics. J. Chem. Phys. 20, 387-394.

Rovira, M., Gimenez, J., Martinez, M., Martinez-Llado, X., de Pablo, J., Marti, V., Duro, L., 2008. Sorption of selenium(IV) and selenium(VI) onto natural iron oxides: Goethite and hematite. J. Hazard. Mater. 150(2), 279-284.

Saikia, J., Saha, B., Das, G., 2011. Efficient removal of chromate and arsenate from individual and mixed system by malachite nanoparticles. J. Hazard. Mater. 186, 575-582.

Saitua, H., Gil, R., Padilla, A.P., 2011. Experimental investigation on arsenic removal with a nanofiltration pilot plant from naturally contaminated groundwater. Desalination 274, 1-6.

Salazar-Camacho, C., Villalobos, M., 2010. Goethite surface reactivity: III. Unifying arsenate adsorption behavior through a variable crystal face - Site density model, Geochim. Cosmochim. Ac. 74, 2257-2280.

Sandoval, R., Cooper, A.M., Aymar, K., Jain, A., Hristovski, K., 2011. Removal of arsenic and methylene blue from water by granulated activated carbon media impregnated with zirconium dioxide nanoparticles. J. Hazard. Mater. 193, 296-303.

Sari, A., Sahinoglu, G., Tuzen, M., 2012. Antimony(III) Adsorption from Aqueous Solution Using Raw Perlite and Mn-Modified Perlite: Equilibrium, Thermodynamic, and Kinetic Studies. Ind. Eng. Chem. Res. 51, 6877-6886. 
Sarkar, S., Blaney, L.M., Gupta, A., Ghosh, D., SenGupta, A.K., 2007. Use of ArsenXnp, a hybrid anion exchanger, for arsenic removal in remote villages in the Indian subcontinent. React. Funct. Polym. 67, 1599-1611.

Sarkar, S., Chatterjee, P.K., Cumbal1, L.H., SenGupta, A.K., 2011. Hybrid ion exchanger supported nanocomposites: Sorption and sensing for environmental applications. Chem. Eng. J. 166, 923-931.

Savage, N., Diallo, M.S., 2005. Nanomaterials and water purification: Opportunities and challenges. J. Nanopart. Res. 7, 331-342.

SenGupta, A.K., Greenleaf, J.E., 2002. Arsenic in Subsurface Water: Its Chemistry and Removal by Engineered Processes, In: SenGupta, A.K. (Ed.), Environmental Separation of Heavy Metals: Engineering Processes. CRC Press, Boca Raton, pp. 265-306.

Shao, W, Li, X, Cao, Q, Luo, F, Li, J, Du, Y, 2008. Adsorption of arsenate and arsenite anions from aqueous medium by using metal(III)-loaded amberlite resins. Hydrometallurgy 91, 138-143.

Sherman, D., 1985. The electronic structures of $\mathrm{Fe}^{3+}$ coordination sites in iron oxides; applications to spectra, bonding, and magnetism. Phys. Chem. Miner. 12, 161-175.

Sherman, D.M., Randall, S.R., 2003. Surface complexation of arsenie(V) to iron(III) (hydr)oxides: Structural mechanism from ab initio molecular geometries and EXAFS spectroscopy. Geochim. Cosmochim. Ac. 67(22), 4223-4230.

Simsek, E. B., Özdemir, E., Beker, U., 2013. Zeolite supported mono- and bimetallic oxides: Promising adsorbents for removal of $\mathrm{As}(\mathrm{V})$ in aqueous solutions. Chem. Eng. J. 220, $402-$ 411.

Smedley, P.L., Kinniburgh, D.G., 2002. A review of the source, behaviour and distribution of arsenic in natural waters. Appl. Geochem. 17, 517-568.

Sontheimer, H., Crittenden, J., Summers, S., 1988. Activated Carbon for Water Treatment, second ed. DVGW-Forschungsstelle, EnglerBunte Institut, Universitat Karlsruhe: Karlsruhe, Germany. 
Sperlich, A., Werner, A., Genz, A., Amy, G., Worch, E., Jekel, M., 2005. Breakthrough behavior of granular ferric hydroxide(GFH) fixed-bed adsorption filters: modeling and experimental approaches. Water Res. 39, 190-198.

Stachowicz, M., Hiemstra, T., van Riemsdijk, W.H., 2008. Multi-competitive interaction of $\mathrm{As}(\mathrm{III})$ and $\mathrm{As}(\mathrm{V})$ oxyanions with $\mathrm{Ca}^{2+}, \mathrm{Mg}^{2+}, \mathrm{PO}_{4}{ }^{3-}$, and $\mathrm{CO}_{3}{ }^{2-}$ ions on goethite, J. Colloid Interf. Sci. 320, 400-414.

Stair, P.C., 1982. The Concept of Lewis Acids and Bases Applied to Surfaces. J. Am. Chem. Soc. 140(15), 4044-4052.

Stair, P.C., 1991. Chemisorption and Surface Reactions from the Lewis Acid-Base Point of View. Langmuir 7, 2508-2513.

Su, H., Puls, R., 2001. Arsenate and Arsenite Removal by Zerovalent Iron: Effects of Phosphate, Silicate, Carbonate, Borate, Sulfate, Chromate, Molybdate, and Nitrate, Relative to Chloride. Environ. Sci. Technol. 35, 4562-4568.

Su, T., Guan, X., Gu, G., Wang, J., 2008. Adsorption characteristics of As(V), Se(IV), and $\mathrm{V}(\mathrm{V})$ onto activated alumina: Effects of $\mathrm{pH}$, surface loading, and ionic strength. J. Colloid Interf. Sci. 326, 347-353.

Su, T., Guan, X., Tang, T., Gu, G., Wang, J., 2010. Predicting competitive adsorption behavior of major toxic anionic elements onto activated alumina: A speciation-based approach. J. Hazard. Mater. 176, 466-72.

Sun, H., Zhang, X., Niu, Q., Chen, Y., Crittenden, J.C., 2007. Enhanced Accumulation of Arsenate in Carp in the Presence of Titanium Dioxide Nanoparticles, Water Air Soil Poll. $178,245-254$.

Sun, X., Hu, C., Qu, J., 2009. Adsorption and removal of arsenite on ordered mesoporous Fe-modified $\mathrm{ZrO}_{2}$. Desalin. Water Treat. 8, 139-145.

Suzuki, T.M., Bomani, J.O., Matsunaga, H., Yokoyama, T., 1997. Removal of As(III) and As $(V)$ by a porous spherical resin loaded with monoclinic hydrous zirconium oxide. Chem. Lett. 11, 1119-1120. 
Sylvester, P., Westerhoff, P., Möller, T., Badruzzaman, M., Boyd, O., 2006. A Hybrid Sorbent Utilizing Nanoparticles of Hydrous Iron Oxide for Arsenic Removal from Drinking Water, Environ. Eng. Sci. 24(1), 104-112.

Szlachta, M., Chubar, N., 2013. The application of Fe-Mn hydrous oxides based adsorbent for removing selenium species from water. Chem. Eng. J. 217, 159-168.

Szrameka, K., Waltera, L.M., McCall, P., 2004. Arsenic mobility in groundwater/surfacewater systems in carbonate-rich Pleistocene glacial drift aquifers (Michigan). Appl. Geochem. 19, 1137-1155.

Tanboonchuy, V., Hsu, J., Grisdanurak, N., Liao, C., 2011. Gas-bubbled nano-zero valent iron process for high concentration arsenate removal. J. Hazard. Mater. 186, 2123-2128.

Thi, T.M., Trang, N.T.H., Anh, N.T.V., 2015. Effects of Mn, Cu doping concentration to the properties of magnetic nanoparticles and arsenic adsorption capacity in wastewater. Appl. Surf. Sci. 340, 166-172.

Torrent, J., Barron, V., Schwertmann, U., 1990. Phosphate adsorption and desorption by goethite differing in crystal morphology. Soil Sci. Soc. Am. J. 54(4), 1007-1012.

Trujillo-Reyes, J., Peralta-Videa, J.R., Gardea-Torresdey, J.L., 2014. Supported and unsupported nanomaterials for water and soil remediation: Are they a useful solution for worldwide pollution, J. Hazard. Mater. 280, 487-503.

Tuna, Ö.A., Özdemir, E., Simsek, E.B., Beker, U., 2013. Removal of As(V) from aqueous solution by activated carbon-based hybrid adsorbents: Impact of experimental conditions. Chem. Eng. J. 223, 116-128.

van der Bruggen, B., Borghgraef, K.C., 2010. Vinckier Causes of Water Supply Problems in Urbanised Regions in Developing Countries. Water Resour. Manag. 24, 1885-1902.

Villalobos, M., Cheney, M.A., Alcaraz-Cienfuegos, J., 2009. Goethite surface reactivity: II. A microscopic site-density model that describes its surface area-normalized variability. J. Colloid Interf. Sci. 336, 412-422.

Vitela-Rodriguez, V., Rangel-Mendez J.R., 2013. Arsenic removal by modified activated carbons with iron hydro(oxide) nanoparticles. J. Environ. Manage. 114, 225-231. 
Walker, G.M., Weatherley, L.R., 1997. Adsorption of acid dyes on to granular activated carbon in fix beds, Water Res. 31(8) 2093-2101.

Waltham, C.A, Eick, M.J., 2002. Kinetics of arsenic adsorption on goethite in the presence of sorbed silicic acid. Soil Sci. Soc. Am. J. 66, 818-825.

Wang, Y.H., Morin, G., Ona-Nguema, G., Juillot, F., Calas, G., Brown, G.E., 2011. Distinctive Arsenic(V) Trapping Modes by Magnetite Nanoparticles Induced by Different Sorption Processes. Environ. Sci. Technol. 45(17), 7258-7266.

Watkins, R., Weiss, D., Dubbin, W., Peel, K., Coles, B., Arnold, T., 2006. Investigations into the kinetics and thermodynamics of $\mathrm{Sb}$ (III) adsorption on goethite $(\alpha-\mathrm{FeOOH})$, J. Colloid Interf. Sci. 303, 639-646.

Waychunas, G.A., Xu, N., Fuller, C.C., Davis, J.A., Bigham, J.M., 1995a. XAS study of $\mathrm{AsO}_{4}{ }^{3-}$ and $\mathrm{SO}_{4}{ }^{2-}$ substituted schwertmannites. Physica B (208-209), 481-483.

Waychunas, G., Davis, J.A., Fuller, C.C., 1995b. Geometry of sorbed arsenate on ferrihydrite and crystallichowdne $\mathrm{FeOOH}$ : Re-evaluation of EXAFS results and topological factors in predicting sorbate geometry, and evidence for monodentate complexes. Geochim. Cosmochim. Ac. 59(17), 3655-3661.

Waychunas, G.A., Rea B.A., Fuller C.C., Davis, J.A., 1993. Surface chemistry of ferrihydrite: Part 1. EXAFS studies of the geometry of coprecipitated and adsorbed arsenate. Geochim. Cosmochim. Ac. 57, 2251-2269.

Weber, T.W., Chakravorty, R.K., 1974. Pore and solid diffusion models for fixed-bed adsorbers. AIChE J. 20, 228-237.

Weber, W.J., Smith, E.H., 1987. Simulation and design model for adsorption processes, Environ. Sci. Technol. 21, 1040-1050.

Wei, X., Bhojappa, S., Lin, L.S., Viadero, R.C., 2012. Performance of Nano-Magnetite for Removal of Selenium from Aqueous Solutions. Environ. Eng. Sci. 26(6), 526-532.

Wescoat, J.L., Headington, L., Theobald, R., 2007. Water and poverty in the United States. Geoforum 38, 801-814. 
Westerhoff, P., De Haan, M., Martindale, A., Mohammad Badruzzaman, M., 2006. Arsenic Adsorptive Media Technology Selection Strategies. Water Qual. Res. J. Can. 41(2), 171-184.

Westerhoff, P., Highfield, D., Badruzzaman, M., Yoon, Y., 2005. Rapid small-scale column tests for arsenate removal in iron oxide packed bed columns. J. Environ. Eng.-ASCE 131(2), 262-271.

Whitman, W., 1923. The two film theory of gas absorption. Chem. Metal. Eng. 29, 146-148.

Wilcox, J.D., Gotkowitz, M.B., Bradbury, K.R., Bahr, J.M., 2010. Using Groundwater Models to Evaluate Strategies for Drinking-Water Protection in Rural Subdivisions. J. Am. Plann. Assoc. 73(3), 295-304.

Wilkie, J.A., Hering, J.G., 1996. Adsorption of arsenic onto hydrous ferric oxide: effects of adsorbate-adsorbent ratios and co-occuring solutes. Colloids Surf. A 107, 97-110.

Xi, J., He, M., Lin, C., 2010. Adsorption of antimony(V) on kaolinite as a function of $\mathrm{pH}$, ionic strength and humic acid. Environ. Earth Sci. 60(4), 715-722.

Xie, B., Fan, M., Banerjee, K., van Leeuwen, J., 2007. Modeling of arsenic(V) adsorption onto granular ferric hydroxide. J. Am. Water Works Assoc. 99(11), 92101.

Xu, P., Zeng, G.M., Huang, D.L., Feng, C.L., Hu, S., Zhao, M.H., Lai, C., Wei, Z., Huang, C., Xie, G.X., Liu, Z.F., 2012. Use of iron oxide nanomaterials in wastewater treatment: A review, Sci. Total Environ. 424, 1-10.

Xu, W., Wang, H., Liu, R., Zhao, X., Qu, J., 2011. Arsenic release from arsenic-bearing FeMn binary oxide: Effects of Eh condition. Chemosphere 83, 1020-1027.

Xu, Z., Cai, J.-G., Pan, B.-C., 2013. Mathematically modeling fixed-bed adsorption in aqueous systems, Univ.-Sci. A Appl. Phys. \& Eng. 14(3), 155-176.

Yan, D., Gang, D.D., Zhang, N., Lin, L.S., 2011. Iron Oxide-Coated GAC Adsorbents: Diffusion-Controlled Sorption of Selenite. Ind. End. Chem. Res. 50(4), 2214-2219.

Yang, L., Dadwhal, M., Shahrivari, Z., Ostwal, M., Liu, P.K.T., Sahimi, M., Tsotsis, T.T., 2006. Adsorption of Arsenic on Layered Double Hydroxides: Effect of the Particle Size. Ind. Eng. Chem. Res. 45(13), 4742-4751. 
Yang, L., Wu, S., Chen, J.P., 2007. Modification of Activated Carbon by Polyaniline for Enhanced Adsorption of Aqueous Arsenate. Ind. Eng. Chem. Res. 46, 2133-2140.

Yang, W., Li, Q., Gao, S., Shang, J.K., 2011. High efficient As(III) removal by selfassembled zinc oxide micro-tubes synthesized by a simple precipitation process. J. Mater. Sci. 46, 5851-5858.

Yin, H., Feng, X., Qiu, G., Tan, W., Liu, F., 2011. Characterization of Co-doped birnessites and application for removal of lead and arsenite. J. Hazard. Mater. 188, 341-349.

Zeng, H., Arashiro, M., Giammar, D.E., 2008b. Effects of water chemistry and flow rate on arsenate removal by adsorption to an iron oxide-based sorbent. Water Res. 42(18), 46294636

Zeng, H., Fisher, B., Giammar, D., 2008a. Individual and Competitive Adsorption of Arsenate and Phosphate To a High-Surface-Area Iron Oxide-Based Sorbent, Environ. Sci. Technol. 42, 147-152.

Zhang, G., Liu, H., Liu, R., Qu, J., 2009a. Removal of phosphate from water by a Fe-Mn binary oxide adsorbent. J. Colloid Interf. Sci. 335, 168-174.

Zhang, L., Liu, N., Yang, L., Lin, Q., 2009b. Sorption behavior of nano- $\mathrm{TiO}_{2}$ for the removal of selenium ions from aqueous solution. J. Hazard. Mater. 170, 1197-1203.

Zhang Q., Crittenden J., Hristovski K., Hand D., Westerhoff P., 2009c. User-oriented batch reactor solutions to the homogeneous surface diffusion model for different activated carbon dosages. Water Res. 43, 1859-1866.

Zhang, Q., Pan, B., Zhang, W., Pan, B., Zhang, Q., Ren H., 2008. Arsenate Removal from Aqueous Media by Nanosized Hydrated Ferric Oxide (HFO)-Loaded Polymeric Sorbents: Effect of HFO Loadings. Ind. Eng. Chem. Res. 47, 3957-3962.

Zhang, Y., Dou, X.M., Yang, M., He, H., Jing, C.Y., Wu, Z.Y., 2010. Removal of arsenate from water by using an $\mathrm{Fe}-\mathrm{Ce}$ oxide adsorbent: Effects of coexistent fluoride and phosphate. J. Hazard. Mater. 179, 208-214. 
Zhang, Y., Yang, M., Dou, X.-M., He, H., Wang, D.-S., 2005. Arsenate Adsorption on an FeCe Bimetal Oxide Adsorbent: Role of Surface Properties. Environ. Sci. Technol. 39, 72467253.

Zheng, Y.-M., Zou, S.-W., Nanayakkara, K.G.N., Matsuura, T., Chen, J.P., 2011. Adsorptive removal of arsenic from aqueous solution by PDVF/zirconia blend flat sheet membrane. J. Membrane Sci. 374, 1-11.

Zhu, J., Pigna, M., Cozzolino, V., Caporale, A.G., Violante, A., 2011. Sorption of arsenite and arsenate on ferrihydrite: effect of organic and inorganic ligands. J. Hazard. Mater. 189, 564-571. 


\section{Figure Caption}

Figure 1. Framework for engineering the next generation of sorbents

Figure 2. Bidentate (a) and monodentate (b) inner-sphere complexes formed between arsenate and ferric (hydr)oxide surface via oxygen bridges

Figure 3. Bidentate corner-sharing (a) and edge-sharing (b) complexes between the tetrahedral structure of arsenate and the octahedral structure of and ferric (hydr)oxide

Figure 4. Mass transport of arsenate from the bulk solution into porous metal (hydr)oxide sorbent 


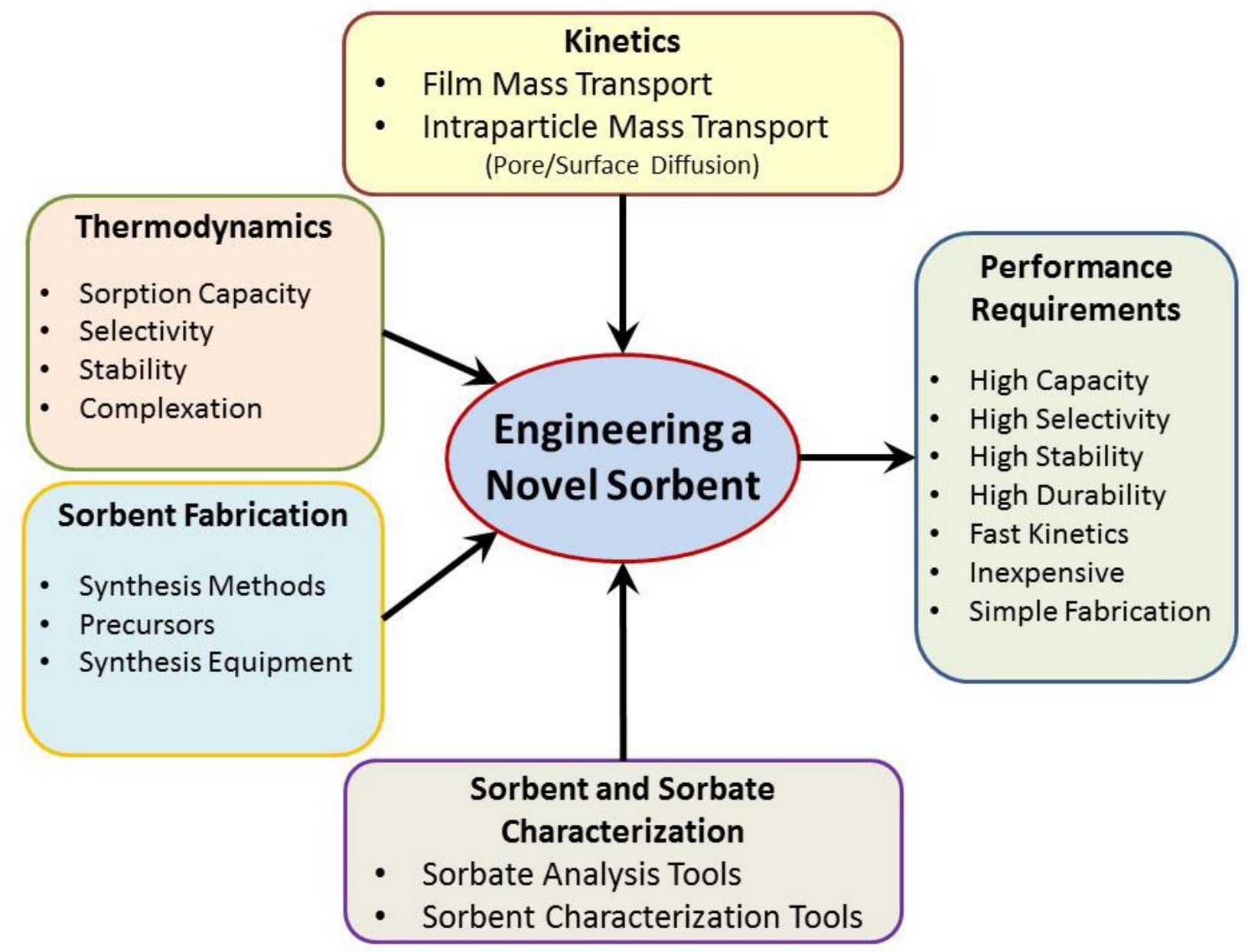

<Figure 1> 

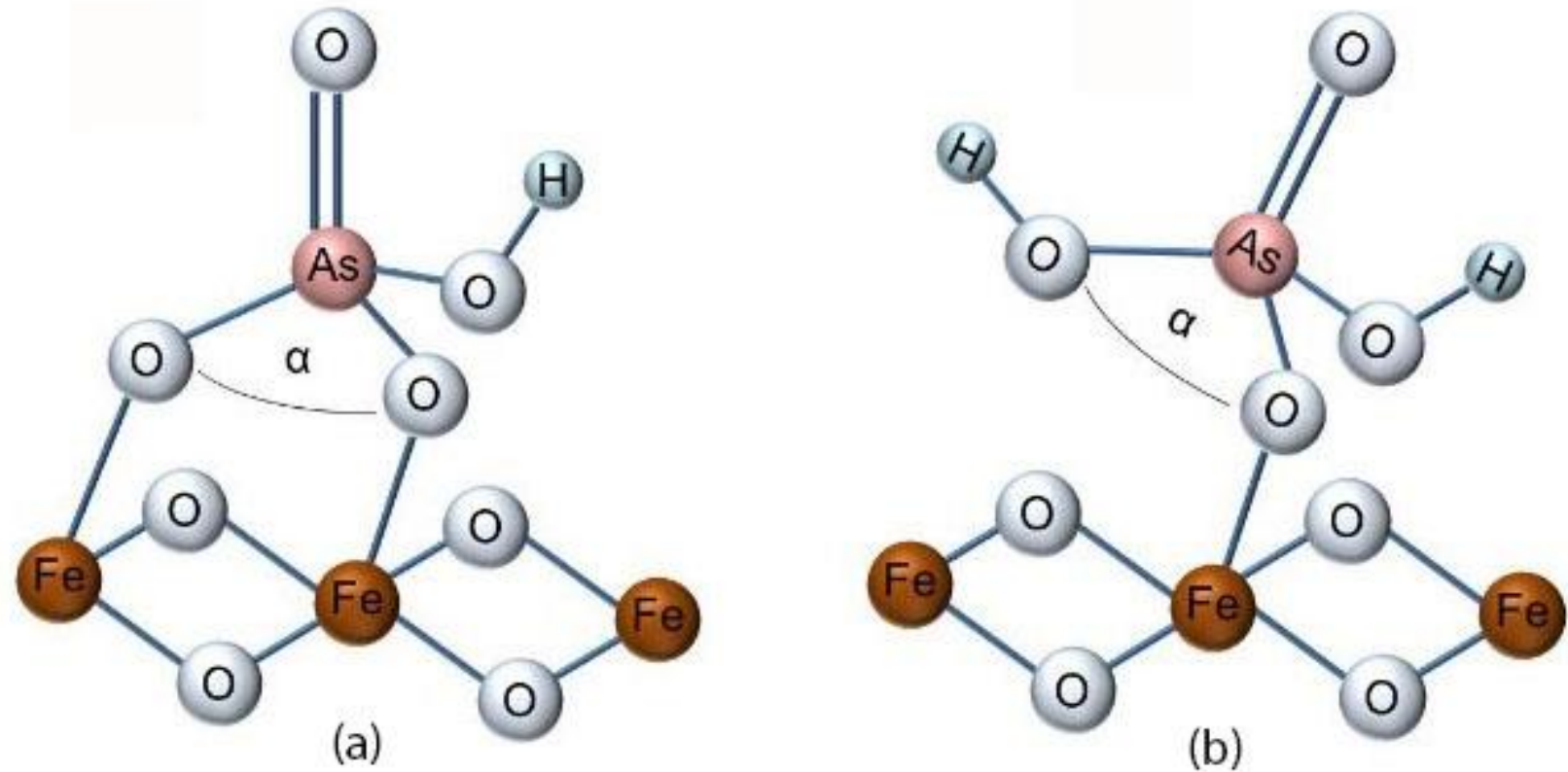

<Figure 2> 

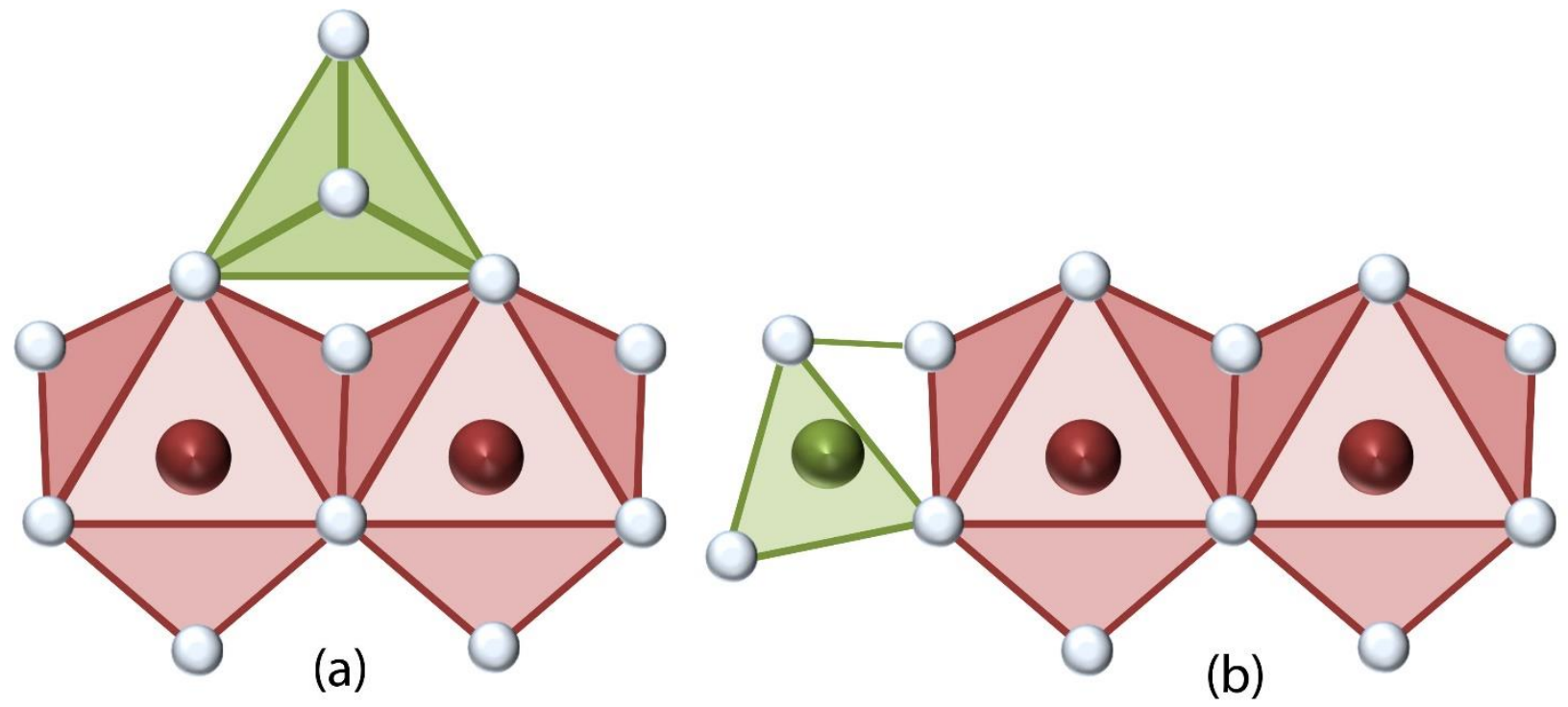

$<$ Figure 3> 


$$
\$
$$




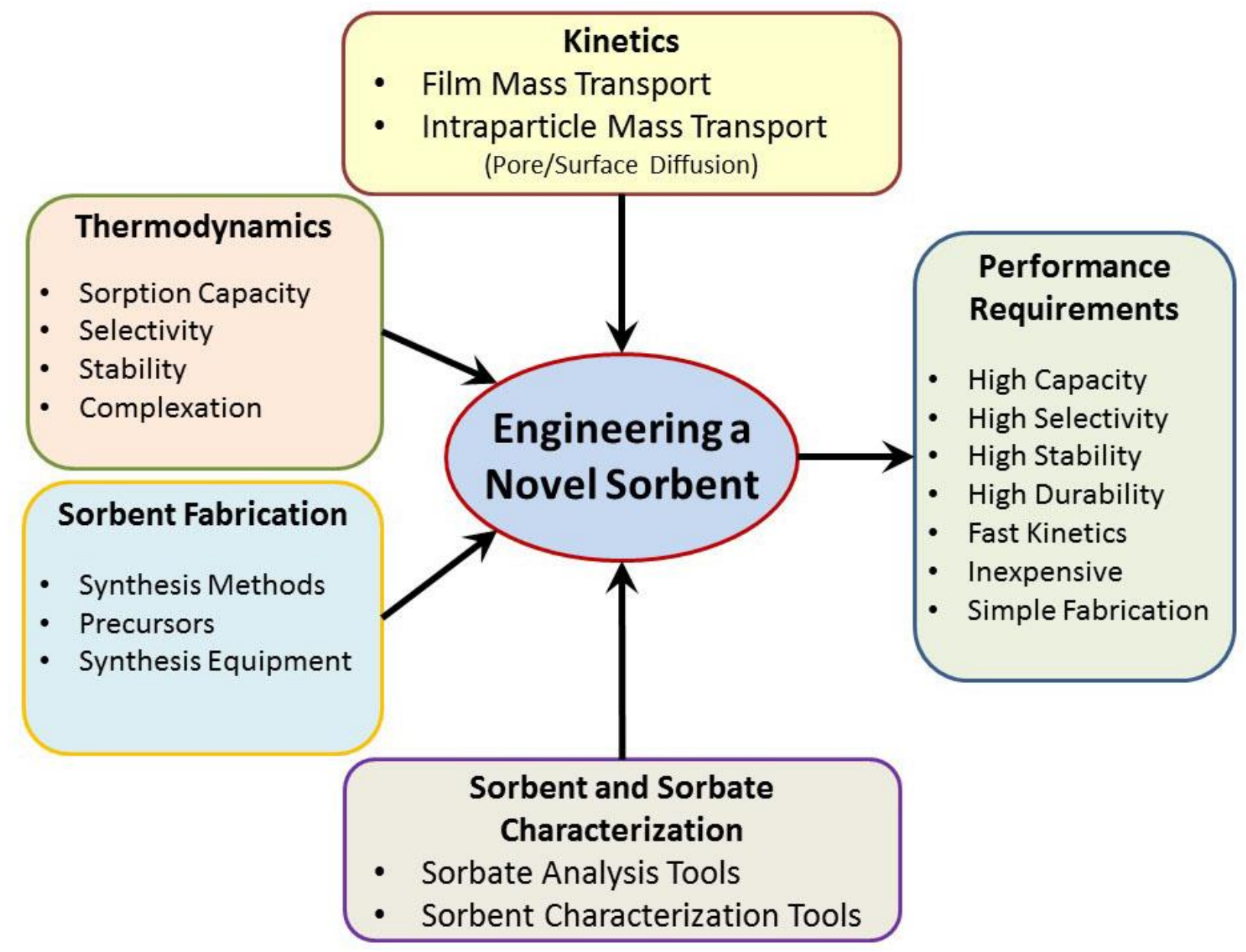

<Graphical abstract> 